\title{
Steam and gas emission rate from La Soufriere volcano, Guadeloupe (Lesser Antilles): Implications for the magmatic supply during degassing unrest
}

\author{
Patrick Allard ${ }^{\mathrm{a}, *}$, Alessandro Aiuppa ${ }^{\mathrm{b}, \mathrm{c}}$, François Beatuducel ${ }^{\mathrm{a}}$, Damien Gaudin ${ }^{\mathrm{d}}$, Rossella Di Napoli ${ }^{\mathrm{b}}$, \\ Sergio Calabrese ${ }^{\mathrm{b}}$, Francesco Parello ${ }^{\mathrm{e}}$, Olivier Crispi ${ }^{\mathrm{e}}$, Gilbert Hammouya ${ }^{\mathrm{e}}$, Giancarlo Tamburello ${ }^{\mathrm{b}}$ \\ a Institut de physique du Globe de Paris, UMR 7154 CNRS, Paris, France \\ ${ }^{\mathrm{b}}$ DiSTeM, Università degli Studi di Palermo, Italy \\ c Istituto Nazionale di Geofisica e Vulcanologia, Sezione di Palermo, Italy \\ d Istituto Nazionale di Geofisica e Vulcanologia, Sezione di Roma, Italy \\ e Observatoire Volcanologique et Sismologique de la Guadeloupe, IPGP, Gourbeyre, Guadeloupe, W.I., France
}

\section{A R T I C L E I N F O}

\section{Article history:}

Received 12 June 2013

Received in revised form 18 June 2014

Accepted 22 June 2014

Available online 1 July 2014

Editor: David R. Hilton

\section{Keywords:}

Soufrière of Guadeloupe

Volcanic gas fluxes

Heat output

Magma degassing budget

Volcanic hazard

\begin{abstract}
A B S T R A C T
Since its last magmatic eruption in 1530 AD, La Soufrière andesitic volcano in Guadeloupe has displayed intense hydrothermal activity and six phreatic eruptive crises. Here we report on the first direct quantification of gas plume emissions from its summit vents, which gradually intensified during the past 20 years. Gas fluxes were determined in March 2006 and March 2012 by measuring the horizontal and vertical distributions of volcanic gas concentrations in the air-diluted plume and scaling to the speed of plume transport. Fluxes in 2006 combine realtime measurements of volcanic $\mathrm{H}_{2} \mathrm{~S}$ concentrations and plume parameters with the composition of the hot $\left(108.5^{\circ} \mathrm{C}\right)$ fumarolic fluid at exit. Fluxes in 2012 result from MultiGAS analysis of $\mathrm{H}_{2} \mathrm{~S}, \mathrm{H}_{2} \mathrm{O}, \mathrm{CO}_{2}, \mathrm{SO}_{2}$ and $\mathrm{H}_{2}$ concentrations, combined with thermal imaging of the plume geometry and dynamics. Measurements were not only focused on the most active South crater (SC) vent, but also targeted Tarissan crater and other reactivating vents. We first demonstrate that all vents are fed by a common $\mathrm{H}_{2} \mathrm{O}$-rich (97-98 mol\%) fluid end-member, emitted almost unmodified at SC but affected by secondary shallow alterations at other vents. Daily fluxes in 2012 averaged 200 tons of $\mathrm{H}_{2} \mathrm{O}, 15$ tons of $\mathrm{CO}_{2}, \sim 4$ tons of $\mathrm{H}_{2} \mathrm{~S}$ and 1 ton of $\mathrm{HCl}$, increased by a factor $\sim 3$ compared to 2006 . Even though modest, such fluxes make La Soufrière the second most important volcanic gas emitter in the Lesser Antilles arc, after Soufriere Hills of Montserrat. Taking account of other hydrothermal manifestations (hot springs and diffuse soil degassing), the summit fumarolic activity is shown to contribute most of the bulk volatile and heat budget of the volcano. The hydrothermal heat output ( $8 \mathrm{MW}$ ) exceeds by orders of magnitude the contemporaneous seismic energy release. Isotopic evidences support that La Soufrière hydrothermal emissions are sustained by a variable but continuous heat and gas supply from a magma reservoir confined at 6-7 km depth. By using petro-geochemical data for La Soufrière magma(s) and their dissolved volatile content, and assuming a magmatic derivation of sulfur, we estimate that the volcanic gas fluxes measured in 2012 could result from the underground release of magmatic gas exsolved from $\sim 1400 \mathrm{~m}^{3} \mathrm{~d}^{-1}$ of basaltic melt feeding the system at depth. We recommend that fumarolic gas flux at La Soufrière becomes regularly measured in the future in order to carefully monitor the temporal evolution of that magmatic supply.
\end{abstract}

(c) 2014 Elsevier B.V. All rights reserved.

\section{Introduction}

Increasing gas emission and compositional changes in fumarolic exhalations are common signals of unrest or even precursors of forthcoming eruption at dormant volcanoes in hydrothermal stage of activity (e.g. Giggenbach and Sheppard, 1989; Symonds et al., 1994, 1996). Deciphering the actual significance of these signals is thus important

\footnotetext{
* Corresponding author at: Institut de physique du Globe de Paris, 1 rue Jussieu, 75238 Paris Cedex 05, France. Tel.: + 33183957630.

E-mail address: pallard@ipgp.fr (P. Allard).
}

to discriminate between pure physical changes in the hydrothermal system regime (e.g. sealing, overpressuring) and evolution due to degassing of upraising magma prone to erupt. Both mechanisms can trigger phreatic eruptions of similar style but with highly contrasted implications. While monitoring fumarolic gas compositions is routinely operated on a number of dormant volcanoes worldwide, quantifying the total gas discharge sustained by fumarolic activity - one key information upon the evolution of volatile and heat budgets - is not trivial. On volcanoes with sustained open-vent magma degassing or/and hosting high-temperature $\left(>400{ }^{\circ} \mathrm{C}\right)$ fumarolic systems, gas discharges are accurately quantified using remote UV spectroscopy of plume 
emissions of sulfur dioxide (e.g., Oppenheimer, 2010). The fluxes of other gas compounds are then calculated from knowledge of fumarole or plume compositions (e.g., Allard et al., 1994). Instead, this approach is prevented at less active $\left(<200-300{ }^{\circ} \mathrm{C}\right)$ degassing systems that emit little $\mathrm{SO}_{2}$ and predominantly $\mathrm{H}_{2} \mathrm{~S}$, this latter being far more difficult to detect optically in volcanic plumes (O'Dwyer et al., 2003). Other techniques for the remote flux sensing of $\mathrm{H}_{2} \mathrm{O}$ and $\mathrm{CO}_{2}$, the two main volcanic gas species, are still in the developing stage (e.g. Fiorani et al., 2011; Schwandner et al., 2012). Alternative possibilities are in situ flux measurement using airborne gas plume profiling (Gerlach et al., 1999) or ground-based eddy gas profiling (Todesco et al., 2003), but these are often hampered by the weakness of air-diluted fumarolic
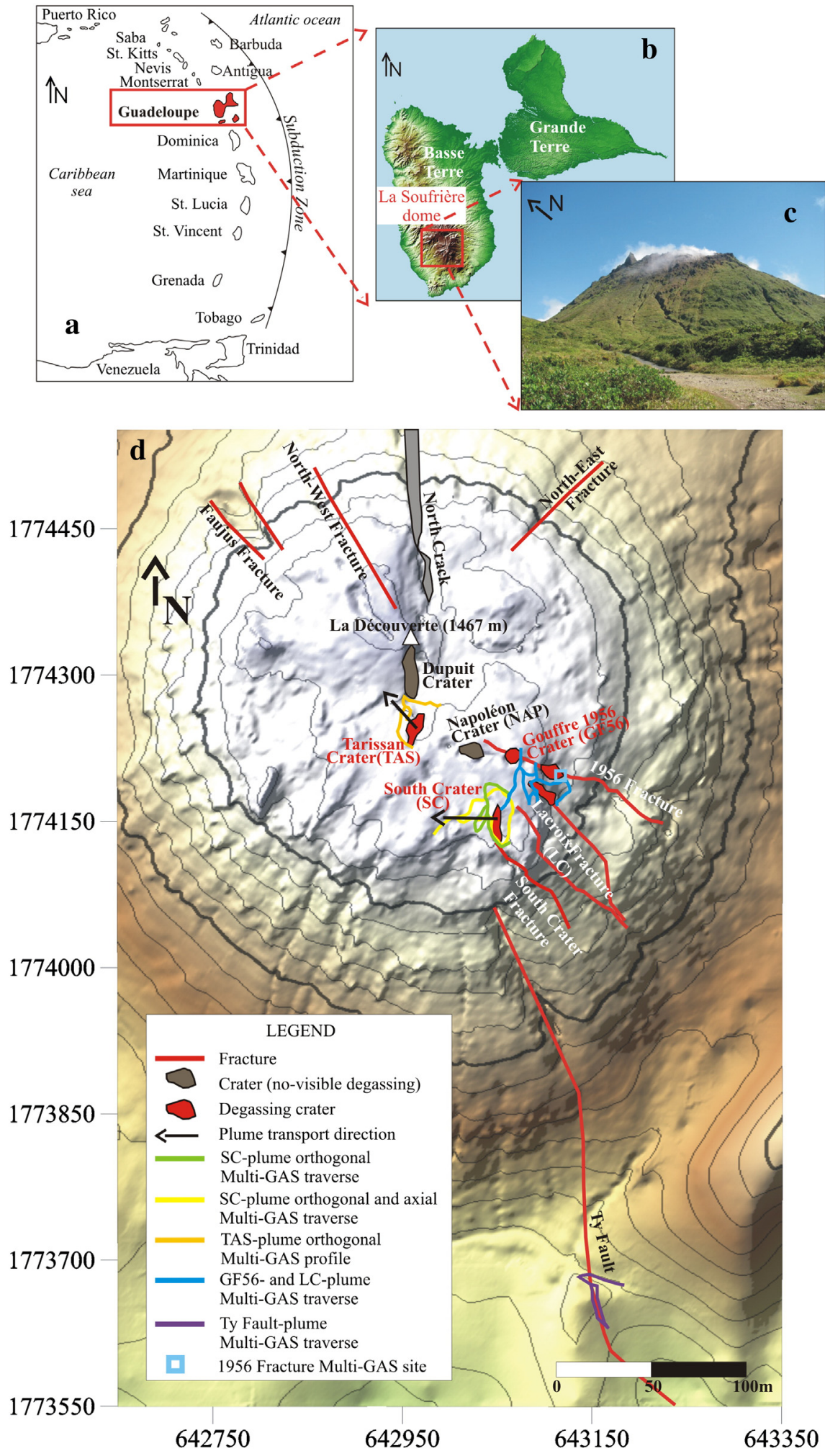

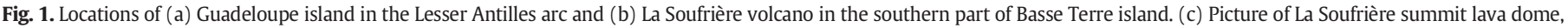

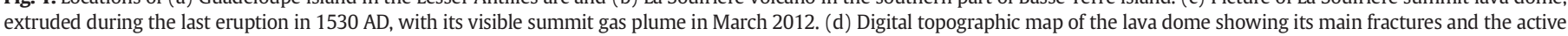
summit fumarolic vents investigated in this study (South Crater: SC; Tarissan crater: TAS; Gouffre 1956: GF56; Lacroix fracture: LC). 
emissions, topographic obstacles and/or too high costs. Therefore, quantitative gas flux evaluation at volcanoes with low-temperature fumarolic activity is scarcely achieved, which deserves new approaches with adequate measuring tools. This is of outmost importance since most dormant volcanic systems worldwide fall in this second category.

One of such systems is La Soufrière volcano in Guadeloupe, in the Lesser Antilles arc (Fig. 1a). La Soufrière is the youngest volcanic relief topping a far larger $\left(\sim 16 \mathrm{~km}^{3}\right)$ and long-lived (>200 ka; Samper et al., 2007) active volcanic complex, the Grande Découverte-Soufrière composite volcano, located in the southern part of Basse Terre island (Boudon et al., 1989; Komorowski et al., 2005; Fig. 1b). It consists of an $\sim 0.05 \mathrm{~km}^{3}$ lava dome that was emplaced during the final stage of the last magmatic eruption in 1530 AD (Boudon et al., 2008). Since then, intense hydrothermal activity (fumaroles, solfataras, hot springs) has persisted on and around the lava dome, and six series of phreatic eruptions happened, the most recent one in 1976-1977 (Le Guern et al., 1980; Feuillard et al., 1983). This activity represents the surface expression of a well-developed hydrothermal system (Le Guern et al., 1980; Zlotnicki et al., 1992; Brombach et al., 2000; Villemant et al., 2005 ) that receives heat and gas from a magma reservoir probably confined at 6-7 km depth beneath the summit (Hirn and Michel, 1979; Pozzi et al., 1979; Semet et al., 1981; Feuillard et al., 1983; Poussineau, 2005). Isotopic investigations actually demonstrate a persistent contribution of magma-derived volatiles to La Soufrière fumarolic gas emissions and thermal waters (Allard et al., 1982; Allard, 1983, 2006; Van Soest et al., 1998; Pedroni et al., 1999; Li et al., 2012; Ruzié et al., 2012, 2013; Jean-Baptiste et al., 2013). Accordingly, the volcano is closely monitored by the local Volcanological and Seismological Observatory (OVSG-IPGP). In particular, its fumarolic gases and thermal springs are routinely sampled and analysed in complement to seismic and geodetic survey (OVSG-IPGP reports, 1992-2012).

Since 1992 a new phase of fumarolic unrest has developed on top of La Soufrière lava dome, in concomitance with renewed shallow seismicity, generating extremely acidic $(\mathrm{Cl}>0.1 \mathrm{~mol} \%)$ chlorine-enriched gas emissions since 1998 (OVSG-IPGP reports, 1992-2012; Villemant et al., 2005; Bernard et al., 2006). Fumarolic emissions have become intense enough to generate a volcanic plume, visible from several kilometres distance during clear days, whose acidity destroys the vegetation (Fig. 1c). This degassing unrest, with progressive reactivation of several summit vents, is still increasing and raises concern about the future evolution of the volcano. However, because the fumarolic fluids contain few $\mathrm{SO}_{2}$ (e.g. OVSG-IPGP reports, 1992-2012; Brombach et al., 2000; Bernard et al., 2006; this work) and the volcanic plume remains too weak to be resolved with remote/airborne techniques, no quantitative gas flux monitoring has ever been set up to complement volcanic hazard assessment. Up to now, only a few indirect attempts were made to assess the fumarolic gas discharge using either velocity measurements at vents or plume modelling from thermal imagery (Beauducel et al., submitted for publication).

Here we report on the first direct quantification of the fumarolic gas discharge from La Soufrière based on real-time gas measurements performed in March 2006 then March 2012. Gas fluxes were obtained by measuring with portable instruments the horizontal and vertical distributions of gas concentrations in cross-sections and along the blowing axis of the volcanic plume, subsequently scaled to the plume transport speed. The hot fumarolic fluid was simultaneously sampled and analysed. Our 2012 dataset, in particular, provides the bulk composition $\left(\mathrm{H}_{2} \mathrm{O}, \mathrm{CO}_{2}, \mathrm{H}_{2} \mathrm{~S}, \mathrm{SO}_{2}\right.$ and $\left.\mathrm{H}_{2}\right)$ of plume emissions from the different vents currently active on top of La Soufrière, measured with a MultiGAS sensor (Aiuppa et al., 2005a), and accurate estimate of the present-day bulk volcanic fluxes based on simultaneous thermal infrared imaging of the plume structure and dynamics. Our results are then discussed in terms of bulk volatile and heat budget, magma degassing supply, and interaction between magma-derived fluids and the hydrothermal system during the current degassing unrest.

\section{La Soufrière volcano}

La Soufrière (Fig. 1) is an $~ 1470$ m-high lava dome made up of crystal-rich andesite $\left(\sim 56 \% \mathrm{SiO}_{2}\right)$ that extruded in former Amic crater at the end of the $1530 \mathrm{AD}$ eruption (Boudon et al., 2008). The eruption initiated with a flank collapse and a sub-Plinian phase accompanied by scoria fallout and pyroclastic flows that involved smaller amounts of more evolved felsic (57-61\% $\mathrm{SiO}_{2}$ ) andesite (Boudon et al., 2008). This eruption is the last major magmatic episode of the so-called La Soufrière activity phase (11,500 B.P. to present) of the Grande Découverte-Soufrière volcanic complex, marked by an alternation of dome-building eruptions, phreatic eruptions, and edifice collapse events leading to emplacement of $0.1-0.5 \mathrm{~km}^{3}$ debris avalanches on the S-SW slopes of the edifice (Boudon et al., 1989; Komorowski et al., 2005). Petro-geochemical data show that the Grande DécouverteSoufrière composite volcano has been fed by a long-lived (>30 ka; Touboul et al., 2007) andesitic magma reservoir, repeatedly replenished from depth with basalt, whose products belong to the same differentiation (crystal fractionation) series as other volcanics from the Basse Terre axial Volcanic Chain and the Mts. Caraïbes basaltic massif to the south (Semet et al., 1981; Boudon et al., 2008). The roof of this reservoir is inferred at about $6-7 \mathrm{~km}$ depth below the summit, or $\sim 5 \pm 0.5 \mathrm{~km}$ below sea level, from both seismic and petrologic data (Hirn and Michel, 1979; Pozzi et al., 1979; Feuillard et al., 1983; Poussineau, 2005; Boudon et al., 2008). Recent seismic tomography of the underlying arc crust (Kopp et al., 2011) shows that such a depth corresponds approximately to the interface between the upper layer of the arc crust, made of volcaniclastic sediments and fractured volcanic rocks, and an $\sim 10 \mathrm{~km}$ thick middle layer composed of denser volcanic/intrusive bodies of felsic to intermediate composition.

The repose period since the $1530 \mathrm{AD}$ eruption has been punctuated by six phreatic eruption phases in 1690, 1797-98, 1812, 1836-37, 1956 and 1976-77. The 1976-1977 eruptive phase provoked the evacuation of 73,000 people for about four months from the southern part of Basse Terre island (Le Guern et al., 1980; Feuillard et al., 1983). Its source mechanism has been the matter of great controversy during the events and still remains debated 38 years later: some authors interpreted this phreatic episode as a failed (still-born) magmatic eruption (Feuillard et al., 1983), possibly involving small magma intrusion that stopped a few kilometres from the surface (Villemant et al., 2005; Boichu et al., 2011), while others argued that it could have resulted from simple destabilization of the hydrothermal system due to either self-sealing pressurization (Le Guern et al., 1980; Zlotnicki et al., 1992) or, instead, depressurization due to tectonic earthquake fracturing (Allard, 2006). Whatever the truth, La Soufriere volcano constitutes a permanent threat for increasingly inhabited areas on its southern slopes, where the towns of Saint-Claude $(10,000)$ and Basse Terre $(40,000)$ stand only 5 and 10 $\mathrm{km}$ from its summit. In particular, pervasive hydrothermal alteration of the lava dome and its highly fractured state enhance the risk of pure gravitational dome failure (Komorowski et al., 2005) that could directly not only affect the surroundings but also decompress the hydrothermal system.

After the 1976-77 events La Soufrière fumarolic activity gradually declined both in intensity and spatial extent: fumarolic manifestations gradually vanished around the lava dome, except along the NNW-SSE regional Ty fault (Fig. 1c), and weakly persisted along previously formed radial fractures of the dome (Fig. 1d). A decrease of both chlorine and sulfate was simultaneously recorded in thermal springs surrounding the lava dome (Bigot and Hammouya, 1987). In 1992, however, fumarolic activity started to intensify again on top of the dome, especially at the 'Southern Crater' fracture vent (SC, Fig. 1d), in coincidence with renewed seismicity. From a gas survey in 1997, Brombach et al. (2000) inferred that the $\mathrm{H}_{2} \mathrm{O}$-dominated fumaroles $\left(\mathrm{T} \sim 93-95{ }^{\circ} \mathrm{C}\right.$ ), with $\mathrm{H}_{2} \mathrm{~S}$ as the main $\mathrm{S}$ species and no detectable $\mathrm{SO}_{2}$ and $\mathrm{HCl}$, were sourced by boiling of $\sim 260^{\circ} \mathrm{C}$ aqueous solutions of the underlying hydrothermal system. Similar temperatures had been inferred from clay 
mineral assemblages present in ash particles emitted during the 1976 eruptive events (Feuillard et al., 1983). But the degassing activity further intensified in 1998, with increasing temperature $\left(\sim 105-110{ }^{\circ} \mathrm{C}\right)$ and the abrupt appearance of $\mathrm{HCl}$ and some $\mathrm{SO}_{2}$ in $\mathrm{SC}$ fumaroles, suggesting that the system was possibly becoming more magmatic in nature (Bernard et al., 2006). A persistent magmatic gas supply to La Soufrière hydrothermal activity is actually demonstrated by the magmatic isotopic signature of chlorine in thermal springs (Li et al., 2012) and by the presence of MORB-type mantle-derived helium $\left({ }^{3} \mathrm{He} /{ }^{4} \mathrm{He}=8.2 \pm 0.2\right.$ Ra; Allard et al., 1982; Allard, 1983; Van Soest et al., 1998; Pedroni et al., 1999; Ruzié et al., 2012, 2013; Jean-Baptiste et al., 2013, submitted for publication) and magma-derived carbon dioxide $\left(\delta^{13} \mathrm{C}=-3.2 \pm\right.$ 0.6\%; Allard et al., 1983; Javoy et al., 1986; Allard, 2006; Ruzié et al., 2013) in gases emitted over the past 35 years. Between 2000 and 2002 the summit fumarolic field expanded, with reactivation of the Tarissan (TAS) and Napoléon (NAP) craters (Fig. 1d). By the time of our March 2006 survey the South Crater (SC) was the main active vent, but in March 2012 degassing had increased at both SC and TAS. Milder but renewed gas release was also occurring at spots along the Gouffre 1956 (GF56; Fig. 1d), formed during the 1956 phreatic eruption, and at Lacroix fracture (LC).

\section{Experimental procedures}

\subsection{Fumarolic gas sampling and analysis}

Since the onset of current degassing unrest at La Soufrière, fumarolic gases have been routinely sampled at SC vent (Fig. 1d) and analysed by the volcano Observatory (OVSG-IPGP reports, 1992-2012). This most active fracture vent is the main source of the volcanic plume and the only one accessible for hot gas sampling. In March 2006 and March 2012 SC fumarolic fluid was issuing at $108.5^{\circ}$ and $107.6^{\circ} \mathrm{C}$, superheated with respect to the temperature of boiling water $\left(96.7^{\circ} \mathrm{C}\right)$ at the elevation. A 3$\mathrm{m}$ long insulated pipe introduced in the vent was used to drain the fluid into pre-evacuated glass bottles, filled with either $\mathrm{P}_{2} \mathrm{O}_{5}$ desiccant or a $\mathrm{NaOH}$ solution, that were connected either directly or in series behind two glass condensers cooled with acetone. The high gas flow rate allowed efficient flushing of the overall sampling line and separate collection of the condensed steam and the 'dry' gas phase. In March 2006 we determined in situ the steam/gas ratio of the fumarolic fluid by repeatedly comparing the collected amount of condensed steam with the amount of 'dry' gas simultaneously pumped into a $250 \mathrm{ml}$ syringe, with a 3-way stopcock, positioned at the open end of the sampling line. In 2012 the $\mathrm{H}_{2} \mathrm{O}$ /gas ratio of the fumarolic fluid was inferred from MultiGAS analysis of near-vent SC volcanic plume (see below).

Gas analyses were performed soon after sampling at the volcano Observatory using a quadrupole mass spectrometer (Balzers Prisma QMS 200). The instrument is configured for routine analysis of $\mathrm{CO}_{2}, \mathrm{H}_{2} \mathrm{~S}$, $\mathrm{SO}_{2}, \mathrm{H}_{2}, \mathrm{CO}, \mathrm{CH}_{4}, \mathrm{~N}_{2}, \mathrm{O}_{2}$, He and $\mathrm{Ar}$, with accurate de-convolution of mass interferences (OVSG-IPGP reports). Concentrations are obtained by calibration with a set of standard gas mixtures and analytical uncertainties ( $\pm 1-5 \%$ for the main components to $\pm 10-20 \%$ for minor components) are determined through Monte-Carlo statistical treatment. $\mathrm{H}_{2} \mathrm{O}$ is determined by gravimetric weighing. The $\mathrm{HCl}$ content of the fumarolic fluid is given by the $\mathrm{Cl}^{-}$content $( \pm 3-5 \%)$ of steam condensates, routinely measured with ion (Dionex) chromatography at the Observatory (OVSG-IPGP reports). The bulk chemical composition of SC fumarolic fluid measured in March 2006 and March 2012 is reported in Table 1.

\subsection{Volcanic plume measurements}

\subsubsection{6 measurements}

Our measurements on 27 March 2006 benefited from excellent, rare weather conditions on top of La Soufriere, where the rainfall rate reaches $\sim 8-10 \mathrm{~m}$ per year and humidity is commonly close to $100 \%$
Table 1

Molar composition of La Soufrière's South Crater (SC) fumarolic fluid in March 2006 and March 2012.

\begin{tabular}{lll}
\hline & $27 / 03 / 2006$ & $07 / 03 / 2012$ \\
\hline $\mathrm{T}^{\circ} \mathrm{C}$ & 108.5 & 107.6 \\
$\mathrm{H}_{2} \mathrm{O}(\mathrm{mol} \%)$ & 97.8 & 96.6 \\
$\mathrm{pH}$ & 0.8 & 0.93 \\
$\mathrm{HCl}$ & 0.3 & 0.37 \\
$\mathrm{Dry}^{\prime}$ gas (mol\%) & 1.9 & 3.0 \\
$\mathrm{CO}_{2}$ & 66.4 & 67.3 \\
$\mathrm{H}_{2} \mathrm{~S}$ & 30.8 & 29.2 \\
$\mathrm{SO}_{2}$ & 0.62 & 0.31 \\
$\mathrm{H}_{2}$ & 0.79 & 0.42 \\
$\mathrm{CH}_{4}$ & 0.08 & 0.19 \\
$\mathrm{CO}$ & 0.007 & 0.003 \\
$\mathrm{~N}_{2}$ & 1.01 & 2.52 \\
$\mathrm{O}_{2}$ & 0.26 & 0.04 \\
$\mathrm{He} \mathrm{ppm}$ & 5.4 & 6.2 \\
$\mathrm{~N}_{2} / \mathrm{Ar}$ & 73 & 78 \\
$\mathrm{H}_{2} \mathrm{O} / \mathrm{H}_{2} \mathrm{~S}$ & 144 & 100 \\
$\mathrm{CO}_{2} / \mathrm{H}_{2} \mathrm{~S}$ & 2.16 & 2.30 \\
$\mathrm{SO}_{2} / \mathrm{H}_{2} \mathrm{~S}$ & 0.02 & 0.01 \\
$\mathrm{HCl}_{3} / \mathrm{H}_{2} \mathrm{~S}$ & 0.48 & 0.38 \\
${ }^{3} \mathrm{He} /{ }^{4} \mathrm{He}\left(\mathrm{R} / \mathrm{R}_{\mathrm{a}}\right)$ & 8.35 & 7.90 \\
$\mathrm{CO}_{2} /{ }^{3} \mathrm{He}$ & $1.1 \mathrm{E}+10$ & $1.0 \mathrm{E}+10$ \\
\hline
\end{tabular}

Chemical analyses performed with quadripole mass spectrometry and ion chromatography (Cl) at the OVSG volcano observatory (see Section 3.1) $\mathrm{H}_{2} \mathrm{O}$ content (and steam/gas ratio) was determined directly in the field in 2006 and indirectly from MultiGAS analysis of SC plume in 2012 (Section 4.1 and Table 2). Helium content and the ${ }^{3} \mathrm{He} /{ }^{4} \mathrm{He}$ ratio (corrected for neon-related air contamination) were determined at LSCE (Saclay, France) using a MAP-215-50 mass spectrometer (Jean-Baptiste et al., 2013, submitted for publication)

(e.g. Chaperon et al., 1985). Regular control with a hand-held meteorological sensor showed a stable ambient pressure of $858.5 \mathrm{hPa}$ and limited variations of air temperature $\left(19\right.$ to $16{ }^{\circ} \mathrm{C}$ ) and relative humidity ( 48 to $60 \%$ ) during our measurements. $\mathrm{E}-\mathrm{W}$ trade winds were blowing at a very constant mean speed of $3.6 \pm 0.2 \mathrm{~m} \mathrm{~s}^{-1}$. Such weather conditions allowed accurate viewing and analysis of the volcanic plume from SC vent (Fig. 2a).

Since $\mathrm{H}_{2} \mathrm{~S}$ is absent in normal atmosphere and the main sulfurbearing species in La Soufrière gases (OVSG-IPGP reports, 1992-2012; Brombach et al., 2000; Bernard et al., 2006; this work), we used it as specific marker of the volcanic plume emission. $\mathrm{H}_{2} \mathrm{~S}$ concentrations (ppmv) in the air-diluted plume were measured in real time using a portable electrochemical sensor (Membrapor $\mathrm{H}_{2} \mathrm{~S} / \mathrm{S}$-type: 0-50 ppmv range, $\pm 2 \%$ accuracy; Aiuppa et al., 2005a), previously calibrated in laboratory. Horizontal and vertical concentration profiles were measured during a traverse orthogonal to the plume direction performed $5 \mathrm{~m}$ downwind SC vent (Fig. 3a-b), then during a profile along the plume axis at 2 to $55 \mathrm{~m}$ distance range from the vent (Fig. $3 c-d$ ). At each point $\mathrm{H}_{2} \mathrm{~S}$ concentration was continuously measured for $1-3 \mathrm{~min}$ in order to obtain a time-averaged value smoothed for short-lived fluctuations in wind turbulence and air dilution of the plume. Horizontal profiling was made with steps of 2.5 to $5 \mathrm{~m}$, depending on topography, and vertical concentration gradients were measured at intervals of $25-50 \mathrm{~cm}$ between the ground and $2.3 \mathrm{~m}$ height (the maximum height of visible plume). GPS site coordinates, wind speed $\left( \pm 0.1 \mathrm{~m} \mathrm{~s}^{-1}\right)$, the plume's temperature $\left( \pm 0.1{ }^{\circ} \mathrm{C}\right)$ and relative humidity $(\mathrm{RH}, \pm 0.1 \%)$ were simultaneously recorded at each point. $\mathrm{RH}$ values are converted into water vapour contents (in $\mathrm{g} \mathrm{m}^{-3}$ ) from the $\mathrm{H}_{2} \mathrm{O}$ partial pressure at corresponding temperature, $P_{\mathrm{H} 2 \mathrm{O}}=P_{\mathrm{s}} * \mathrm{RH} / 100$, where the vapour saturation pressure $P_{\mathrm{s}}=610.78 * \exp [17.2694 \mathrm{t} /(\mathrm{t}+238.3)]$. As discussed thereafter, the volcanic flux of $\mathrm{H}_{2} \mathrm{~S}$ is determined by integrating the horizontal and vertical distributions of $\mathrm{H}_{2} \mathrm{~S}$ concentrations within the volcanic plume and then scaling to the wind speed.

\subsubsection{2 measurements}

Our measurements on top of La Soufrière were performed on 5-7 March 2012 under more unstable weather conditions, with ambient 


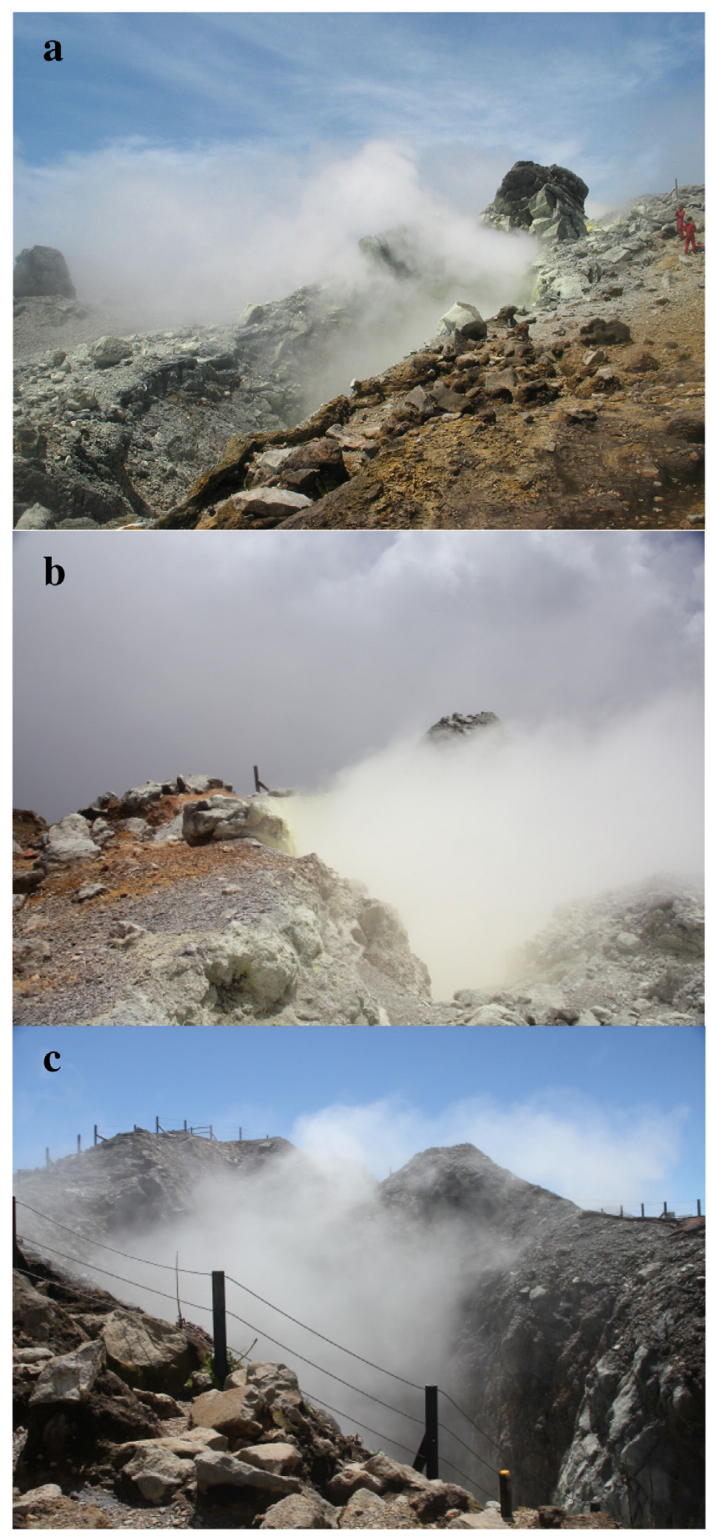

Fig. 2. Photos of South Crater (SC) vent in (a) March 2006 and (b) March 2012, and (c) of Tarissan crater (TAS) in March 2012 (P. Allard).

pressure of $845 \mathrm{hPa}$, temperature of $14-16{ }^{\circ} \mathrm{C}$, relative humidity of $\sim 85 \%$, and measured wind speed varying from 27 to $6 \mathrm{~m} \mathrm{~s}^{-1}$ from day to day. Our key improvement during that survey was to measure simultaneously the within-plume concentrations of both $\mathrm{H}_{2} \mathrm{~S}, \mathrm{H}_{2} \mathrm{O}, \mathrm{CO}_{2}, \mathrm{SO}_{2}$ and $\mathrm{H}_{2}$ with a portable INGV-type MultiGAS analyser (a recent description of the instrument's setup and performance can be found in Aiuppa et al., 2011, 2012). Since its advent (Aiuppa et al., 2005a,b; Shinohara, 2005), this custom-made gas sensor box has become a widely used, robust tool for volcanic gas studies and monitoring (see Aiuppa et al., 2011; Roberts et al., 2012 for an updated list of references). On La Soufrière we used two light $(<3 \mathrm{~kg})$ MultiGAS instruments which permit high-rate ( $0.5 \mathrm{~Hz}$ ) real-time detection of $\mathrm{H}_{2} \mathrm{O}$ and $\mathrm{CO}_{2}$ with NDIR spectroscopy and of $\mathrm{SO}_{2}, \mathrm{H}_{2} \mathrm{~S}$ and $\mathrm{H}_{2}$ with electrochemical sensors (Aiuppa et al., 2012). The precision on concentrations is typically $\pm 5-10 \%$.

The instruments, carried in backpacks, were operated in the walking traverse mode, with their flexible tubing inlet being positioned so as to suck plume/background air from the desired height above the ground.
Measurements performed at the different vents active on La Soufrière lava dome (Fig. 1d) allowed us to characterise the compositional differences of their gas emissions (Table 2) and to compare them with the fumarolic fluid simultaneously sampled at SC crater (Table 1). For gas flux quantification we measured the air-diluted volcanic plumes from both SC and TAS craters (Fig. 2b,c), the two most active vents. Acquiring gas concentration data at $0.5 \mathrm{~Hz}$ and simultaneous GPS positioning, the MultiGAS had the required temporal/spatial resolution to map the chemical heterogeneity of the volcanic plumes. We first performed air background measurements (upwind the active vents) then in-plume concentration measurements (Fig. 1d) during repeated orthogonal (A-D in Fig. 4a,b) and co-axial (X-Y in Fig. 4a,c) traverses relative to the westerly plume transport direction, at distances of 0 to $\sim 60 \mathrm{~m}$ of each vent. We also checked the vertical distribution of gas concentrations between 0 and 3.5 $\mathrm{m}$ above the ground. As a whole, $\mathrm{H}_{2} \mathrm{O}, \mathrm{CO}_{2}, \mathrm{SO}_{2}, \mathrm{H}_{2} \mathrm{~S}$ and $\mathrm{H}_{2}$ concentrations were determined at $>5000$ positions and stored in the onboard memory. With respect to our March 2006 survey, we thus obtained a far larger sampling grid and for five gas species simultaneously. Bernard et al. (2006) had previously performed near-vent plume measurements on La Soufrière with a portable analyser but only along co-axial profiles, at a low time resolution $(0.017 \mathrm{~Hz})$, and without any gas flux assessment. Instead, here we combine our results for both orthogonal and axial gas concentration profiles with the wind speed to derive accurate constraints on the fumarolic gas discharge in 2012.

The plume's thickness and transport velocity were additionally determined from infrared thermal imaging, using an Infratec model VarioCAM HR head 410 camera. This camera works with uncooled microbolorometer sensors in the infrared range 7.5-14 $\mu \mathrm{m}$, at $<0.08 \mathrm{~K}$ sensitivity in the -40 to $120{ }^{\circ} \mathrm{C}$ temperature range, and produces $384 \times 288$ pixel images with a $15^{\circ} \times 12^{\circ}$ optical lens. The system is able to acquire temperature images at $1 \mathrm{~Hz}$ sampling or to make screenshot movies at 25 frame/s rate with fixed temperature colour-map. We positioned the camera a few tens of metres away from SC and TAS vents, looking plumes laterally, and we recorded short movies in the same time as MultiGAS measurements. We repeatedly considered $2 \mathrm{~s}$-long movies, from which we extracted 50 frames and then computed a grid of velocity vectors for each couple of images using a particle image velocimetry (PIV) algorithm (Mori and Chang, 2003). The camera's small shakings due to wind were corrected using vectors on the ground part of each image.

\subsection{Soil gas flux measurements}

In addition to fumarolic emissions, intense diffuse soil degassing has been recognized at the southeastern base of La Soufrière lava dome (Allard et al., 1998), in a hydrothermal area aligned on the Ty fault volcano-tectonic structure that cuts the dome (Fig. 1). In March 2006 we re-determined the $\mathrm{CO}_{2}$ concentrations ( $\pm 3 \%, \mathrm{ADC}$ LFG20 portable infrared spectrometer) and temperatures at 30$70 \mathrm{~cm}$ depth in the ground in this area, along a $110 \mathrm{~m}$ long profile crossing the Ty fault (Citerne road), and measured for the first time the $\mathrm{CO}_{2}$ fluxes from the volcanic ground. $\mathrm{CO}_{2}$ fluxes $( \pm 5-7 \%$ ) were measured at the soil interface (and corrected for ambient pressure) using a West Systems accumulation chamber coupled to a previously calibrated Drager infrared spectrometer, as previously described by Chiodini et al. (1998). Further $\mathrm{CO}_{2}$ flux investigations were realized on the lava dome itself, along the walking paths circling the dome (Sentier des Dames and Col de l'Echelle) and, punctually, near SC vent on top of the dome. Most of the lava dome being covered with abundant vegetation, a volcanic flux anomaly was considered to be significant when as much as three times the measured biogenic $\mathrm{CO}_{2}$ flux background. The results are discussed in Section 5.3 and depicted in Fig. 9. 

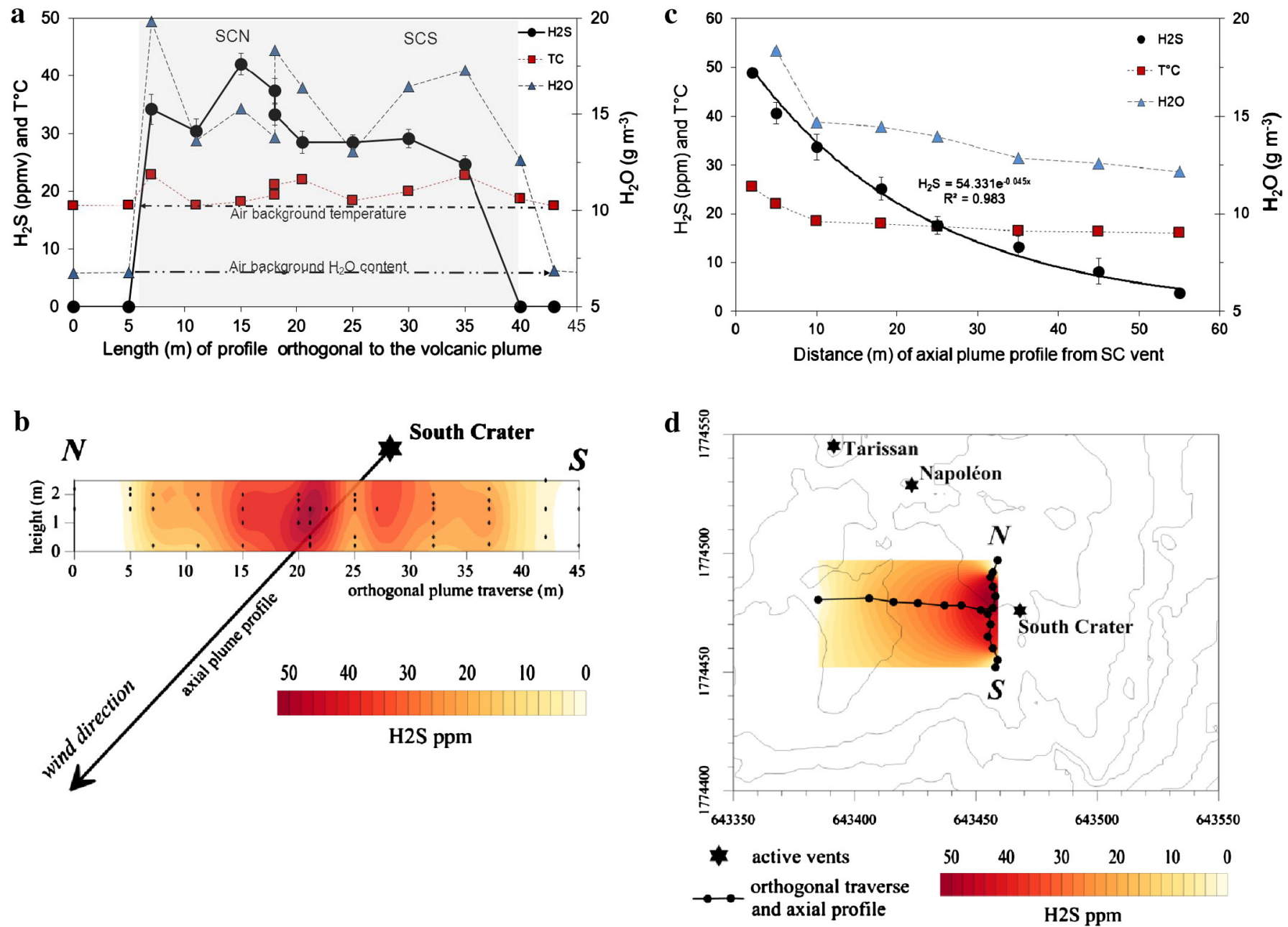

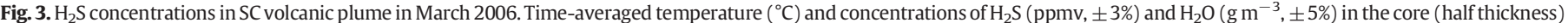

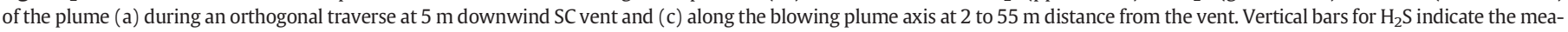

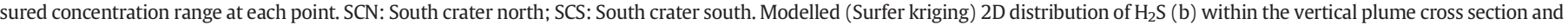
(d) along the horizontal blowing direction during plume dilution and transport. See text for details and discussion.

\section{Results}

\subsection{Chemical composition of La Soufrière hot fumarolic fluid}

Table 1 shows the molar composition of the fumarolic fluid directly sampled from SC vent in March 2006 and March 2012. The steam/gas volume ratio of 45 (i.e., 45 litres of steam for one litre of gas) measured in March 2006 highlights the water-rich composition (97.8 mol\%) of La Soufrière fumarolic fluids (Le Guern et al., 1980; Brombach et al., 2000; Bagnato et al., 2009). Although not directly measured in March 2012, a comparable water content of $96.6 \pm 0.5 \mathrm{~mol} \%$ is inferred from our MultiGAS data for SC volcanic plume (see Section 4.3 and Table 2). $\mathrm{HCl}$ ranges from 0.3 to $0.4 \mathrm{~mol} \%$ of the bulk fluid, accounting for the high acidity of the fumarolic emissions. For the sake of comparison, the

Table 2

Molar ratios and bulk composition of gas plume exhalations from active vents at La Soufrière in March 2012, as measured with MultiGAS.

\begin{tabular}{|c|c|c|c|c|c|c|c|c|c|c|c|}
\hline Date & Site & $\mathrm{H}_{2} \mathrm{O} / \mathrm{H}_{2} \mathrm{~S}$ & $\mathrm{CO}_{2} / \mathrm{H}_{2} \mathrm{~S}$ & $\mathrm{SO}_{2} / \mathrm{H}_{2} \mathrm{~S}$ & $\mathrm{H}_{2} / \mathrm{H}_{2} \mathrm{~S}$ & $\mathrm{H}_{2} \mathrm{O} / \mathrm{CO}_{2}$ & $\mathrm{H}_{2} \mathrm{O} \%$ & $\mathrm{CO}_{2} \%$ & $\mathrm{H}_{2} \mathrm{~S} \%$ & $\mathrm{SO}_{2} \%$ & $\mathrm{H}_{2} \%$ \\
\hline 05/03/2012 am & Southern crater & 108 & 2.2 & 0.040 & 0.013 & 49.4 & 97.1 & 2.0 & 0.9 & 0.036 & 0.012 \\
\hline $05 / 03 / 2012 \mathrm{pm}$ & Southern crater & 88 & 2.7 & 0.040 & nd & 32.8 & 95.9 & 2.9 & 1.1 & 0.044 & nd \\
\hline 07/03/2012 am & Southern crater & 99 & 2.7 & 0.036 & 0.018 & 36.8 & 96.4 & 2.6 & 1.0 & 0.035 & 0.018 \\
\hline 07/03/2012 pm & Southern crater & 106 & 2.4 & 0.025 & nd & 44.5 & 96.9 & 2.2 & 0.9 & 0.023 & nd \\
\hline $07 / 03 / 2012 \mathrm{am}$ & Gouffre 1956 & 87 & 2.8 & 0.044 & nd & 31.7 & 95.8 & 3.0 & 1.1 & 0.049 & nd \\
\hline $07 / 03 / 2012 \mathrm{am}$ & Lacroix inf vent & 168 & 2.8 & 0.016 & nd & 59.4 & 97.8 & 1.6 & 0.6 & 0.009 & nd \\
\hline 07/03/2012 am & Lacroix sup vent & 247 & 6.0 & 0.025 & nd & 40.9 & 97.2 & 2.4 & 0.4 & 0.010 & nd \\
\hline $07 / 03 / 2012 \mathrm{pm}$ & Lacroix sup vent & 260 & 6.5 & 0.029 & nd & 39.9 & 97.2 & 2.4 & 0.4 & 0.011 & nd \\
\hline $05 / 03 / 2012 \mathrm{am}$ & Tarissan crater & 263 & 4.8 & n.d & 0.010 & 54.7 & 97.8 & 1.8 & 0.4 & nd & 0.004 \\
\hline $05 / 03 / 2012 \mathrm{pm}$ & Tarissan crater & 147 & 4.2 & n.d & nd & 34.9 & 96.6 & 2.8 & 0.7 & nd & nd \\
\hline 07/03/2012 am & Tarissan crater & 127 & 5.2 & 0.005 & 0.013 & 24.4 & 95.3 & 3.9 & 0.8 & 0.004 & 0.009 \\
\hline $07 / 03 / 2012 \mathrm{pm}$ & Tarissan crater & 85 & 4.1 & 0.003 & nd & 20.7 & 94.3 & 4.6 & 1.1 & 0.003 & nd \\
\hline $05 / 03 / 2012 \mathrm{pm}$ & Ty fault & 16 & 24.5 & 0.001 & 0.011 & 0.7 & 38.7 & 58.8 & 2.4 & 0.002 & 0.027 \\
\hline
\end{tabular}

nd: not detected. 

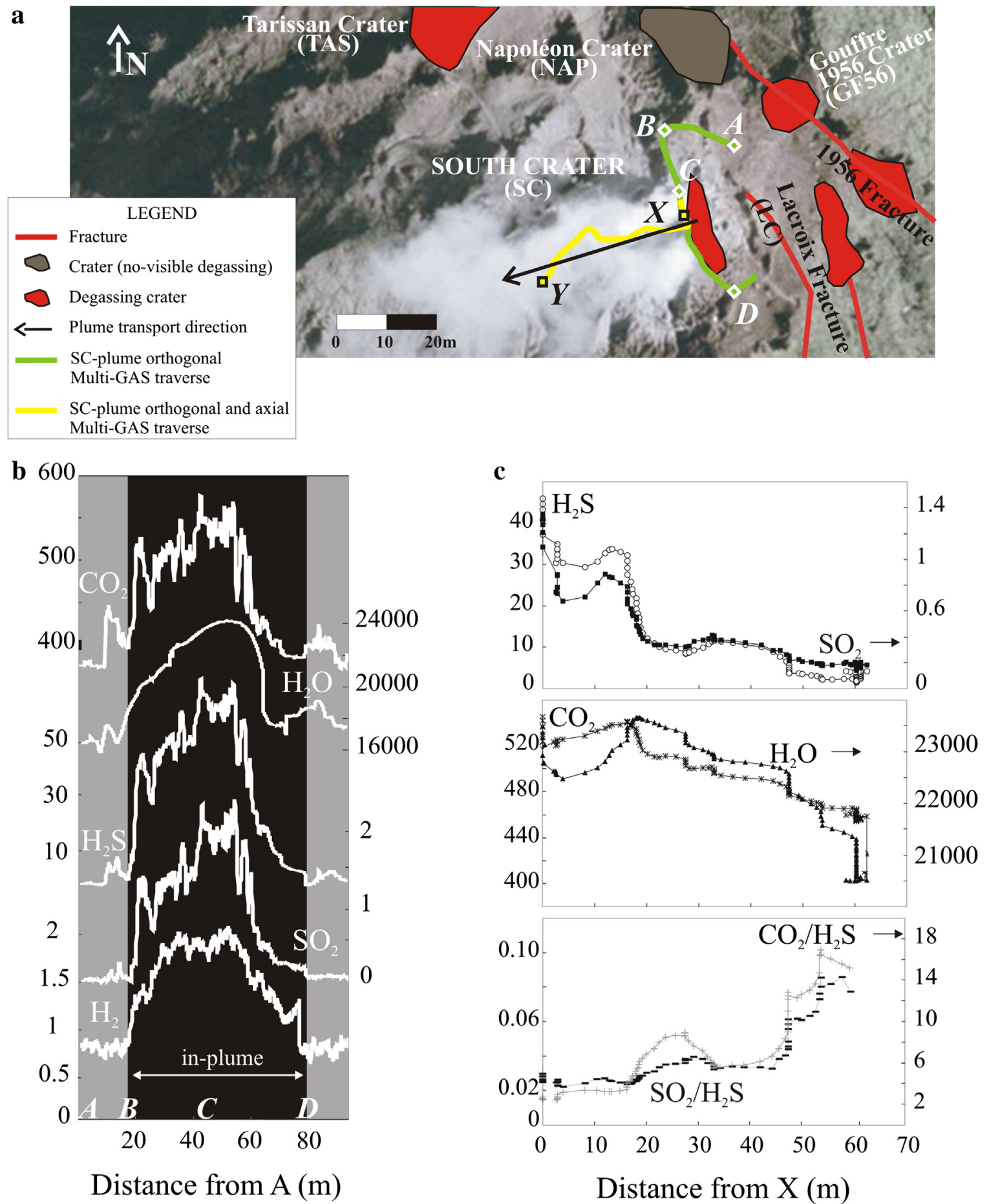

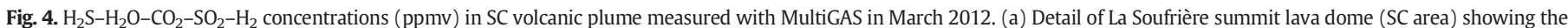

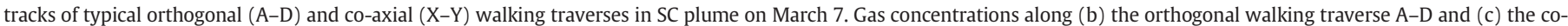
axial traverse $\mathrm{X}-\mathrm{Y}$. Travelled distances (in metre) from start-point of the tracks (A and $\mathrm{X}$ ) are shown on the $\mathrm{X}$-axis.

concentrations of other gas species are reported in Table 1 as molar percentages of the 100\%-normalized 'dry' gas phase. Low $\mathrm{N}_{2}$ and $\mathrm{O}_{2}$ amounts demonstrate minor air contamination, essentially from ambient atmosphere according to $\mathrm{N}_{2} / \mathrm{Ar}$ ratios that are close to the air ratio (83). Carbon dioxide is the main gas species, followed by $\mathrm{H}_{2} \mathrm{~S}, \mathrm{H}_{2}$ and $\mathrm{SO}_{2} . \mathrm{CH}_{4}$ and $\mathrm{CO}$ are the minor components. Despite enhanced degassing, SC fumarolic fluid in March 2006 and March 2012 displays a broadly similar composition, with steady $\mathrm{CO}_{2} / \mathrm{H}_{2} \mathrm{~S}$ and $\mathrm{CO}_{2} / \mathrm{HCl}$ ratios and high $\mathrm{H}_{2} \mathrm{~S} / \mathrm{SO}_{2}$ ratio. Finally, helium is highly enriched with respect to its potential contribution from contaminating air, in agreement with its MORB-type ${ }^{3} \mathrm{He} /{ }^{4} \mathrm{He}$ ratio (7.9 to $8.3 \mathrm{Ra}$; Table 1 ). Instead, the average $\mathrm{CO}_{2} /{ }^{3} \mathrm{He}$ molar ratio of $10^{10}$ (corrected for air contamination) is about 5 times higher than the mean ratio in MORB mantle $(2.2 \pm$ $0.4 \times 10^{9}$; Marty and Tolstikhin, 1998). Such a high ratio indicates an ultimate crustal derivation of about $80 \%$ of the emitted carbon dioxide, most likely from the subducted slab according to geochemical evidences of a subducted sediment contribution to magma genesis under the arc (Van Soest et al., 1998; Pedroni et al., 1999, and references therein). A 
subducted sedimentary contribution is also compatible with the higher mean $\delta^{13} \mathrm{C}\left(-3.2 \pm 0.6 \%\right.$ of La Soufrière $\mathrm{CO}_{2}$ compared to typical MORB upper mantle carbon ( -8 to $-5 \%$; Allard, 1983, 2006; Javoy et al., 1986; Ruzié et al., 2013).

\subsection{March 2006 plume observations}

Fig. 3a shows the time-averaged distributions of $\mathrm{H}_{2} \mathrm{~S}$ (ppmv), water vapour $\left(\mathrm{g} \mathrm{m}^{-3}\right)$ and temperature $\left({ }^{\circ} \mathrm{C}\right)$ in the core (at half thickness) of La Soufrière (SC) volcanic plume in March 2006, as retrieved from our traverse orthogonal to the blowing plume direction only $5 \mathrm{~m}$ downwind $\mathrm{SC}$ fracture vent. The volcanic plume cross-section is well defined by the data. At the onset of our traverse, the lack of $\mathrm{H}_{2} \mathrm{~S}$ and the $\mathrm{T}-\mathrm{H}_{2} \mathrm{O}$ air values are representative of pure background atmosphere previously measured upwind of the vent. The sharp increase of $\mathrm{H}_{2} \mathrm{~S}$ and water vapour, together with temperature, after $5 \mathrm{~m}$ of the profile and their drop back to air values after about $40 \mathrm{~m}$ distance (Fig. 3a) delineate a maximum width of $35 \mathrm{~m}$ for the plume cross-section. Measurements of the vertical distribution of the three parameters at each point constrain an average plume thickness of $2 \mathrm{~m}$ : no $\mathrm{H}_{2} \mathrm{~S}$ and pure air background $\mathrm{T}$ and $\mathrm{RH}$ values were generally detected at $\leq 0.2$ and $\geq 2.2 \mathrm{~m}$ height above the ground, except during occasional turbulent wind fluctuations. $\mathrm{H}_{2} \mathrm{~S}$ iso-contours drawn by applying geostatistical kriging (Surface Mapping System Surfer software, Version 8) to our horizontal and vertical data set verify that the core of the plume, characterized by maximum $\mathrm{H}_{2} \mathrm{~S}$ concentrations, stands at between 1 and $2 \mathrm{~m}$ height above ground level (Fig. 3b). Statistical processing just tends to overestimate $\mathrm{H}_{2} \mathrm{~S}$ concentration at maximum height where our number of data points is more limited. In the core portion of the plume, $\mathrm{H}_{2} \mathrm{~S}, \mathrm{H}_{2} \mathrm{O}$ and temperature display very parallel variations (Fig. 3a) and, in agreement with field observations, their average values evidence a more intense fumarolic supply from the northern section (SCN) than southern section (SCS) of SC fracture vent (Fig. 3a and b). $\mathrm{H}_{2} \mathrm{~S}$ varies between 24.7 and 42.0 ppmv, $\mathrm{H}_{2} \mathrm{O}$ between 12.6 and $19.8 \mathrm{~g} \mathrm{~m}^{-3}$ ( $\mathrm{RH}$ from $79.3 \%$ to 97.7\%), and temperature between 17.8 (ambient) and $22.9{ }^{\circ} \mathrm{C}$. Comparing these plume features to the characteristics of the fumarolic fluid at exit ( $108.5{ }^{\circ} \mathrm{C}, 97.8 \mathrm{~mol} \% \mathrm{H}_{2} \mathrm{O}$ and 5900 ppmv $\mathrm{H}_{2} \mathrm{~S}$; Table 1 ) highlights how the latter becomes rapidly air-diluted and cooled upon emission, through turbulent expansion and mixing: the maximum $\mathrm{H}_{2} \mathrm{~S}$ plume content of 42 ppmv points to an air dilution factor of 140 only $5 \mathrm{~m}$ downwind of the vent under stable weather conditions. However, while being strongly air-diluted the volcanic plume remains $2-3{ }^{\circ} \mathrm{C}$ hotter than ambient atmosphere and thus produces a clear thermal anomaly in infrared imaging (see below and Beauducel et al., submitted for publication).

Fig. 3c shows the evolutions of $\mathrm{H}_{2} \mathrm{~S}, \mathrm{H}_{2} \mathrm{O}$ and temperature in the core of SC plume ( $1.5 \mathrm{~m}$ height above the ground) along its blowing axis at distances of 2 to $55 \mathrm{~m}$ from SC northern vent (SCN, point $15 \mathrm{~m}$ on $\mathrm{x}$-axis of Fig. 3a). Over that path length one observes a quite regular, exponential decrease of $\mathrm{H}_{2} \mathrm{~S}$ from 49 to 3.8 ppmv, which in first order fits with pure air dilution during plume dispersion from a linear gas source under the measured atmospheric conditions (Pasquill, 1961). Bernard et al. (2006) reported a similar $\mathrm{H}_{2} \mathrm{~S}$ trend in SC plume in September 2004 , but with lower absolute concentrations (e.g., 8 ppmv compared to $\sim 30 \mathrm{ppmv}$ at $15 \mathrm{~m}$ distance from $\mathrm{SC}$ ) which may reflect either a lower emission rate at that time or/and more efficient air-dilution of the plume due to much higher wind speed $\left(12 \mathrm{~m} \mathrm{~s}^{-1}\right)$ during their measurement. In the very first part of our profile (2-10 $\mathrm{m}$ from the vent) the decrease of $\mathrm{H}_{2} \mathrm{~S}$ is paralleled by a rapid decrease of both temperature (from 22 to $18.5^{\circ} \mathrm{C}$ ) and water vapour (Fig. 3c). Afterwards, the plume gradually reaches the contemporaneous air background temperature ( $16{ }^{\circ} \mathrm{C}$ by the end of the day), while its vapour content remains at a high level (14-12 $\mathrm{g} \mathrm{m}^{-3}$, i.e. RH 95-90\%). Such a pattern is well explained by entrainment of air moisture during plume dilution. Fig. 3d shows the modelled 2-D horizontal evolution of $\mathrm{H}_{2} \mathrm{~S}$ iso-contours during SC plume dispersion and dilution obtained by geostatistical kriging of our results for both the orthogonal traverse and the axial profile at the plume's core height.

\subsection{March 2012 MultiGAS observations}

MultiGAS measurements in March 2012 allowed us to determine the $\mathrm{H}_{2} \mathrm{O}-\mathrm{CO}_{2}-\mathrm{H}_{2} \mathrm{~S}-\mathrm{SO}_{2}-\mathrm{H}_{2}$ composition of gases issuing from each of the active vents (Table 2) and then to determine the total plume fluxes from both SC and TAS craters. Below we focus on results for SC vent, the most active one. Fig. 4a-b shows a typical traverse orthogonal to the transport direction of SC plume, obtained on March 7. In the upwind side of the profile (from A to B) and outside the plume's margins, $\mathrm{SO}_{2}$ and $\mathrm{H}_{2} \mathrm{~S}$ are at or below the detection limit $(<0.1 \mathrm{ppm})$ and the relatively stable concentrations of $\mathrm{H}_{2} \mathrm{O}(\sim 17,000$ ppmv $), \mathrm{CO}_{2}(\sim 385 \mathrm{ppmv})$ and $\mathrm{H}_{2}(\sim 0.7 \mathrm{ppmv})$ are representative for air background on top of the volcano. As the plume is intercepted (B) the concentration of all gas species consistently increases, reaches its maximum at the plume axis ( $\mathrm{C}$ in Fig. $4 \mathrm{~b}$ ), then returns to nearly-background values at the end of the plume's encounter (D). Note that $\mathrm{H}_{2} \mathrm{~S}$ displays a much higher plume/ background contrast $(\sim 700)$ than $\mathrm{CO}_{2}(\sim 3.3)$ and $\mathrm{H}_{2} \mathrm{O}(\sim 1.3)$ at the plume axis. In the plume cross section $\mathrm{B}-\mathrm{D}(\sim 60 \mathrm{~m}$ wide $)$ all gases but $\mathrm{H}_{2} \mathrm{O}$ exhibit rapid oscillations, illustrating the fast response of the sensors to variable plume density (pulsations in plume speed and direction). The far less nervous behaviour of $\mathrm{H}_{2} \mathrm{O}$ is consistent with both its higher content in the volcanic fluid and the high relative humidity (as high as 94\%) of ambient air. Because the plume was so close to vapour saturation and partial condensation, we cannot exclude some vapour loss (as condensed water) in the instrument's pipeline. This means that our measurements may underestimate to some (likely minor) extent the real $\mathrm{H}_{2} \mathrm{O}$ emission. All the orthogonal traverses performed at SC during March 5-7 yielded similar output as that shown in Fig. 4b (a cumulative $\mathrm{H}_{2} \mathrm{~S}$ concentration profile obtained by summing the results of all the traverses is shown in Fig. 5d).

Fig. 4c shows the results of a typical axial profile performed on March 7 along the blowing direction and in the core of SC plume. Over the explored distance range ( $\sim \mathrm{m}$ from vent at $\mathrm{X}$ to $\sim 70 \mathrm{~m}$ at $\mathrm{Y}$; Fig. $4 a, c)$ the concentration of all measured gases decreases with increasing distance, even though with an irregular pattern in the first 20 $\mathrm{m}$. As the profile end is approached, all gas concentrations have fallen to low levels (e.g., $\mathrm{H}_{2} \mathrm{~S} \sim 2 \mathrm{ppm}, \mathrm{SO}_{2} \sim 0.1 \mathrm{ppm}$ ) but still above the air background. Such a spatial trend is consistent with increasing air dilution of the volcanic plume. However, Fig. 4c also shows that while $\mathrm{SO}_{2} / \mathrm{H}_{2} \mathrm{~S}$ and $\mathrm{CO}_{2} / \mathrm{H}_{2} \mathrm{~S}$ ratios remain low and stable until about $20 \mathrm{~m}$ from the vent, they monotonically increase at higher distance, with a sharper rate after $45 \mathrm{~m}$. This pattern points to $\mathrm{H}_{2} \mathrm{~S}$ depletion relative to $\mathrm{CO}_{2}$ and $\mathrm{SO}_{2}$ after short plume transport time, evidencing that $\mathrm{H}_{2} \mathrm{~S}$ oxidation in tropical wet volcanic plumes is much faster than observed in colder and less humid environments (e.g., Italy; Aiuppa et al., 2005b, 2007). This observation implies that our $\mathrm{H}_{2} \mathrm{~S}$-based flux assessment in March 2006 is reliable for only near-vent $(<20 \mathrm{~m})$ plume measurements (see thereafter).

In order to explore the variability of gas concentrations along vertical cross-section(s) of the plume, we performed a number of vertical MultiGAS profiles by sequentially moving the instrument's inlet from the ground level up to $\sim 3.5 \mathrm{~m}$ height. Fig. 5e gives an illustration of the variations in $\mathrm{H}_{2} \mathrm{~S}$ concentration measured at a fixed position in the core of the SC plume (site C in Fig. 4a,b). One sees that the bulk of the plume was captured between $\sim 0.5$ and $\sim 3 \mathrm{~m}$ height above the ground, with maximum $\mathrm{H}_{2} \mathrm{~S}$ concentrations of $\sim 50 \mathrm{ppm}$. The spread of concentrations recorded at any given height reflects the temporal variations in plume density resulting from instantaneous random changes in wind strength and direction. Low $\mathrm{H}_{2} \mathrm{~S}$ concentrations (down to background level) at heights of $<0.5 \mathrm{~m}$ and $\leq 3.5 \mathrm{~m}$ above the ground (Fig. 5d) verify that the volcanic plume was essentially confined at close-to-ground level during our MultiGAS measurements (average 


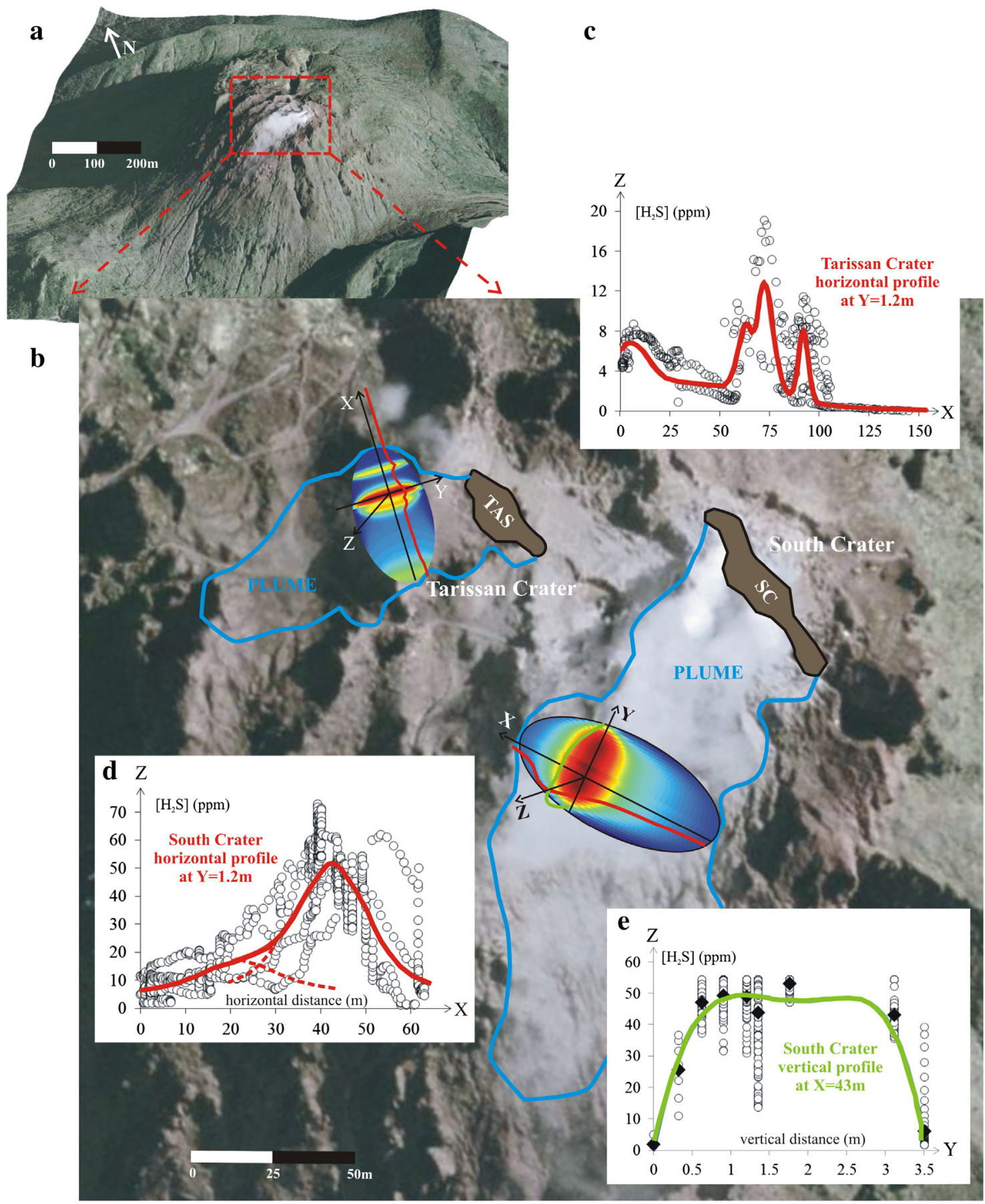

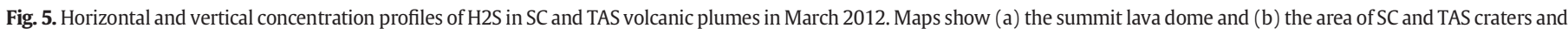

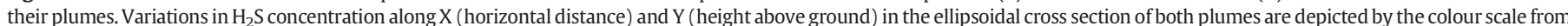

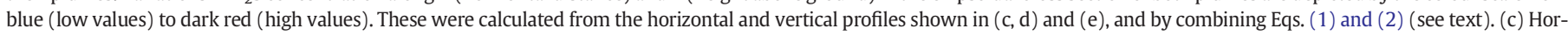

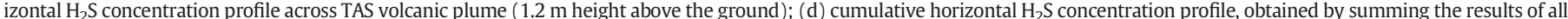

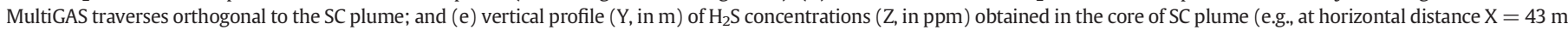
from A, along the track A-D of Fig. 4).

thickness $\leq 2.5 \mathrm{~m}$ ) and, therefore, that we were able to capture most of the volcanic gas discharge.

\subsection{IR-camera observations}

The IR camera was positioned at $80 \mathrm{~m}$ NNW from the plume arising from the SC fracture, in order to get a complete lateral plume viewing. Fig. 6 a shows a representative example of the velocity vectors calculated from each couple of images and the particle image velocimetry (PIV) algorithm (Mori and Chang, 2003). We observe a vertical gradient in horizontal speed from $5 \mathrm{~m} / \mathrm{s}$ at ground level to $15 \mathrm{~m} / \mathrm{s}$ at the top of the plume, with a mean value of $7.6 \mathrm{~m} \mathrm{~s}^{-1}$ at height of the plume's core. Comparable wind speeds $\left(7-14 \mathrm{~m} \mathrm{~s}^{-1}\right)$ were measured at the same time and at heights of $1.5-2.5 \mathrm{~m}$ in the plume using a hand-held anemometer. Our image analysis of other $2 \mathrm{~s}$ IR camera movies provided us with similar ranges and average velocities as in Fig. 6a. We 

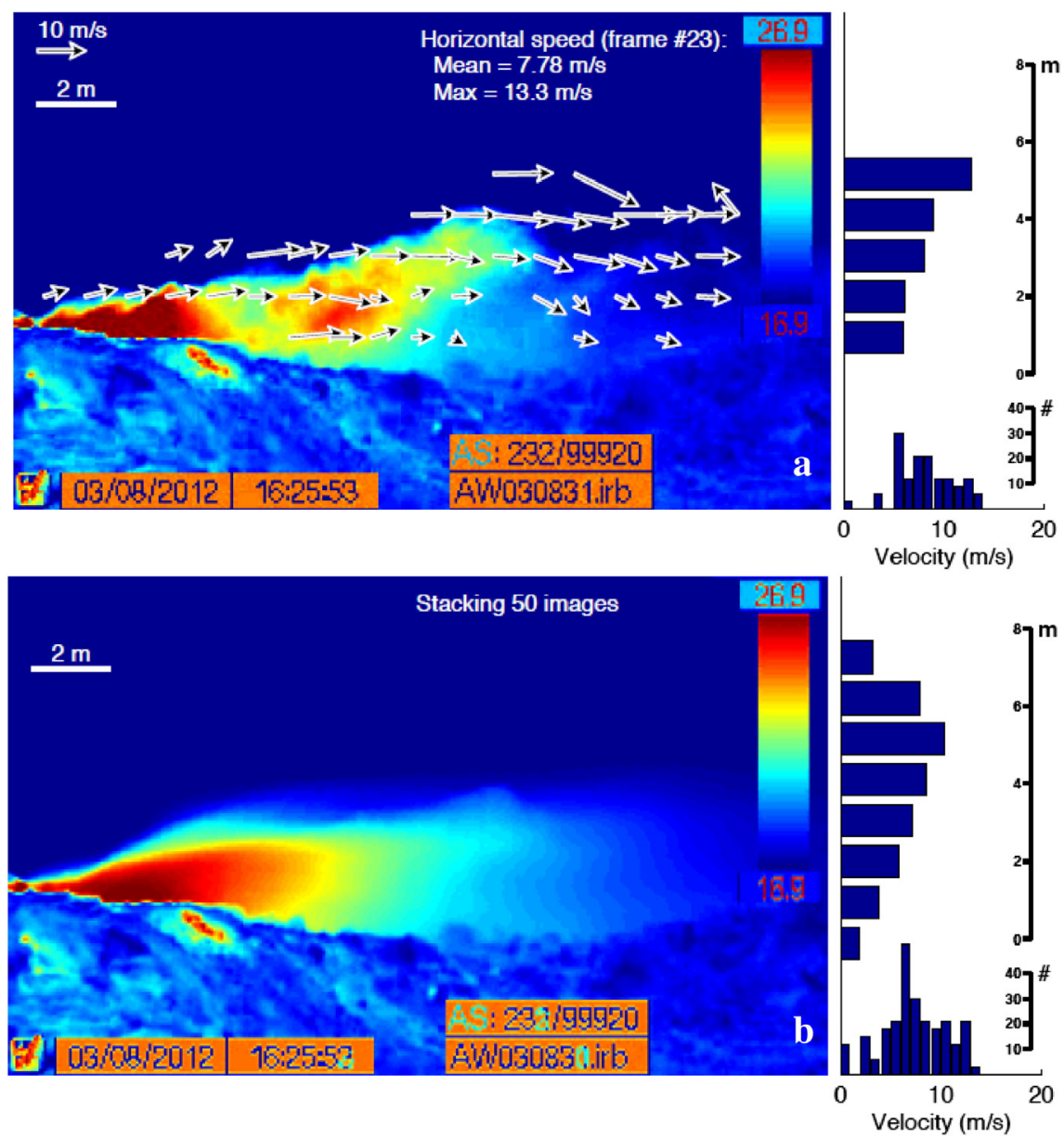

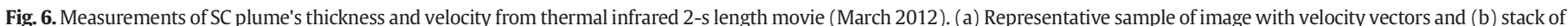
the 50 images. Graphs on the right: (y-axis) mean values of velocity for each elevation layer, (x-axis) histogram of velocities.

therefore use a mean plume velocity of $7 \mathrm{~m} \mathrm{~s}^{-1}$ in all calculations below (cfr. 5.2).

To determine the plume thickness, we calculated a stack of $50 \mathrm{im}$ ages, corrected for camera shaking using vectors on the ground part of each image. The results displayed in Fig. $6 \mathrm{~b}$ constrain an average plume height of $3.5 \mathrm{~m}$, in fair agreement with the highest plume thickness inferred from MultiGAS measurements (Fig. 5e).

\section{Discussion}

\subsection{Vent-to-vent gas comparison}

Our MultiGAS data for the different active vents of La Soufrière lava dome in March 2012 allow the very first comparison of their gas emissions at a same time. Data for each vent were combined to draw gas/ $\mathrm{H}_{2} \mathrm{~S}$ correlation plots, since $\mathrm{H}_{2} \mathrm{~S}$ is the best volcanic marker (with highest plume/background contrast; Section 4.3). Fig. 7 illustrates the coherent distributions between $\mathrm{H}_{2} \mathrm{~S}$ and the four other gas species in SC plume, based on the dataset presented in Fig. 4. The gradient of the best-fit regression line in the concentration plots provides the average gas $/ \mathrm{H}_{2} \mathrm{~S}$ molar ratios of the emitted volcanic gas (e.g. Aiuppa et al., 2011). Table 2 lists the average chemical ratios and hence the molar gas composition obtained for each vent.

Our results demonstrate a substantial vent-to-vent variability of La Soufrière gas emissions. Plume emissions from SC vent confirm the release of a water-dominated volcanic gas ( 96-97\%), with $2.0-2.9 \%$ $\mathrm{CO}_{2}$ and $\sim 1 \% \mathrm{H}_{2} \mathrm{~S}$ (Table 2). When compared to the hot fumarolic fluid sampled simultaneously (Table 1 ), SC plume displays similar $\mathrm{CO}_{2} / \mathrm{H}_{2} \mathrm{~S}$
(2.2-2.7 vs 2.3) and $\mathrm{H}_{2} / \mathrm{H}_{2} \mathrm{~S}(0.013-0.018$ vs 0.0145$)$ ratios, which verifies a good conservation of $\mathrm{H}_{2} \mathrm{~S}$ at short transport range. Its higher $\mathrm{SO}_{2} / \mathrm{H}_{2} \mathrm{~S}$ ratio (0.025-0.04) than in the hot fluid (0.010-0.013) thus suggests some partial loss (dissolution, precipitation) of poorly abundant $\mathrm{SO}_{2}$ in collected samples of the hot fluid prior to their analysis. The Gouffre 1956 (GF56) is found to emit the same gas as SC (Table 2), despite its far lower emissivity. In contrast, the exhalations from TAS and LC have much higher $\mathrm{CO}_{2} / \mathrm{H}_{2} \mathrm{~S}$ ratios (4.1-5.2 and 2.8-6.5, respectively) and $\mathrm{H}_{2} \mathrm{O} / \mathrm{H}_{2} \mathrm{~S}$ ratios (85-263 and $168-260$, respectively).

These compositional differences amongst the vents are clearly depicted in a scatter diagram of $\mathrm{H}_{2} \mathrm{O} / \mathrm{CO}_{2}$ versus $\mathrm{H}_{2} \mathrm{O} / \mathrm{S}$ (Fig. 8), in which La Soufrière data are also compared with other volcanic gas compositions in the Lesser Antilles arc. Two interesting observations arise from this diagram:

a) Each Soufrière vent defines a characteristic, nearly linear data trend along which the gas composition varies from water-rich $\left(\mathrm{H}_{2} \mathrm{O} / \mathrm{CO}_{2}>40\right)$ to water-poorer $\left(\mathrm{H}_{2} \mathrm{O} / \mathrm{CO}_{2}<20\right)$ at almost constant $\mathrm{CO}_{2} / \mathrm{S}$ ( or $\mathrm{CO}_{2} / \mathrm{H}_{2} \mathrm{~S}$ ) molar ratio. Such linear patterns indicate that most of the compositional variability at individual vent is governed by variable extent of water-loss from or water-addition to an otherwise steady gas phase (constant $\mathrm{C} / \mathrm{S}$ ratio). Water loss can arise from steam condensation (in the ground, or prior to sensing by the MultiGAS) and water gain can result from variable incorporation of external meteoric water into either the feeding conduits or the plume.

b) Instead, the differences in $\mathrm{CO}_{2} / \mathrm{S}$ ratio amongst the vents are best explained by variable extent of sulfur loss from an originally common volcanic gas (Fig. 8). For instance, S-poor gases from TAS can be 


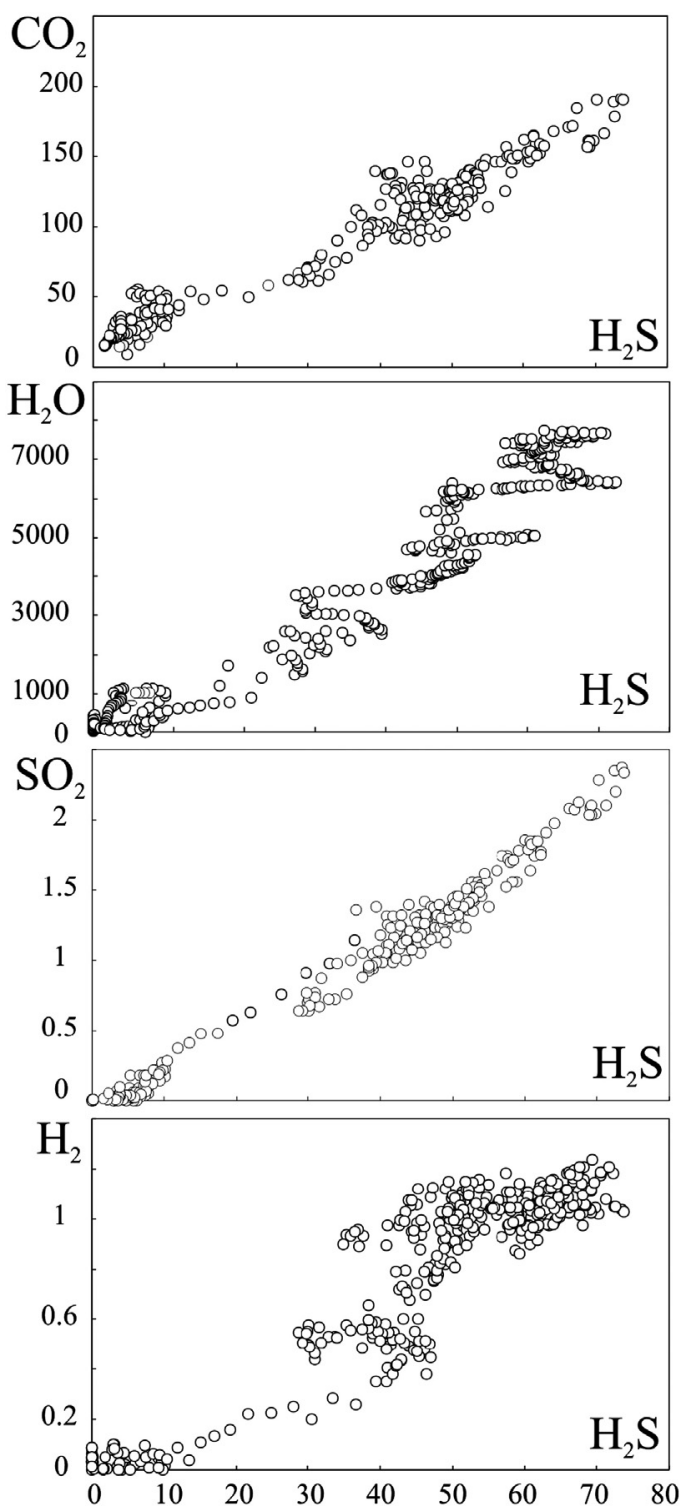

Fig. 7. Gas $-\mathrm{H}_{2} \mathrm{~S}$ scatter plots for SC plume from MultiGAS dataset of Fig. 4b. Gas $/ \mathrm{H}_{2} \mathrm{~S}$ average ratios (Table 2 ) were obtained from the gradient of the best-fit regression lines.

interpreted as resulting from $45 \%$ mean S removal from a SC-type gas. The TAS crater actually hosts an acidic boiling lake $\left(\mathrm{T} \sim 98{ }^{\circ} \mathrm{C}\right.$, $\mathrm{pH}=-0.46$ in March 2012) at $\sim 85 \mathrm{~m}$ depth below its rim; sulfur scrubbing during gas-lake interaction can thus easily explain both the higher $\mathrm{CO}_{2} / \mathrm{H}_{2} \mathrm{~S}$ ratio and the marked $\mathrm{SO}_{2}$-depletion of its plume emissions (Table 2), as well as their high variability in $\mathrm{H}_{2} \mathrm{O}$. Hydrothermal degassing along the Ty fault at the base of the lava dome, characterized by a cluster of steaming vents with low flow rate ( $\mathrm{T}=30$ to $95{ }^{\circ} \mathrm{C}$ ) and warm grounds, display the largest $\mathrm{CO}_{2} / \mathrm{H}_{2} \mathrm{~S}$ (24.5) and lowest $\mathrm{H}_{2} \mathrm{O} / \mathrm{CO}_{2}$ (0.7) ratios (Fig. 8), consistent with extensive steam condensation and solid sulfur deposition in the local volcanic ground.

Our observations thus reveal significant compositional differences amongst La Soufrière vents, due to secondary and likely shallow alterations. The most pristine volcanic fluid is emitted from the most active SC vent. A limited influence of sulfur scrubbing at this vent in March 2012 is supported by the fact that SC fumarolic emission has a comparable $\mathrm{CO}_{2} / \mathrm{S}$ ratio as high-temperature $\left(740{ }^{\circ} \mathrm{C}\right)$ magmatic gas directly collected in 1996 from the extruding andesitic lava dome of Soufrière Hills in Montserrat (Hammouya et al., 1998), three weeks before the first pyroclastic flows. Note also that in 1997, prior to intensification of the current degassing unrest, SC fumaroles were a factor $\sim 5$ poorer in sulfur $\left(\mathrm{CO}_{2} / \mathrm{H}_{2} \mathrm{~S} \sim 10\right)$ than in March 2006 and 2012 (Fig. 8). Clearly, this increased $\mathrm{S}$ content claims for either (i) highly reduced sulfur scrubbing compared to 1997, (ii) enhanced S remobilisation from the hydrothermal system, or/and (iii) increased sulfur supply from the degassing magma reservoir at depth, as discussed in Section 5.4.

\subsection{Fumarolic gas fluxes}

The volcanic gas flux in March 2006 was computed by integrating the horizontal and vertical distributions of $\mathrm{H}_{2} \mathrm{~S}$ in SC plume crosssection (Fig. 3b) and then multiplying by the wind speed. From the integrated amount of $\mathrm{H}_{2} \mathrm{~S}$ in the plume cross-section $\left(2610 \mathrm{ppm} \cdot \mathrm{m}^{2}\right)$, an average wind speed of $3.6 \pm 0.2 \mathrm{~m} \mathrm{~s}^{-1}$ and the molecular weight of $\mathrm{H}_{2} \mathrm{~S}(0.034 \mathrm{~kg})$, we obtain an $\mathrm{H}_{2} \mathrm{~S}$ output of $0.0127 \pm 0.007 \mathrm{~kg} \mathrm{~s}^{-1}$ or $1.1 \pm 0.2$ tons per day ( $\mathrm{t} / \mathrm{d}$, Table 3$)$. Scaling the composition of SC hot fumarolic fluid (Table 1 ) to this $\mathrm{H}_{2} \mathrm{~S}$ flux of $\sim 1 \mathrm{t} / \mathrm{d}$, we then compute daily mean fluxes of 75 tons of $\mathrm{H}_{2} \mathrm{O}, 2.8$ tons of $\mathrm{CO}_{2}, 0.45$ tons of $\mathrm{HCl}$, 0.04 tons of $\mathrm{SO}_{2}$ and 0.0014 tons of $\mathrm{H}_{2}$ (Table 3). We estimate an overall uncertainty of $\pm 30 \%$ on these fluxes from the propagation of analytical errors. Water vapour contributes $94 \%$ of the total fluid output $(80 \mathrm{t} / \mathrm{d})$.

Our much larger dataset and for five gas species measured with MultiGAS in March 2012 allows improved flux quantification. We limit here our analysis to SC and TAS, by far the two main degassing vents; degassing at GF56 and LC vents was too weak for allowing any reliable in-plume traverse and, according to visual observations, contributes negligibly to the overall gas output. To calculate the volcanic gas flux we focus again on $\mathrm{H}_{2} \mathrm{~S}$, the best volcanic marker. We computed the integrated amount (IA) of $\mathrm{H}_{2} \mathrm{~S}$ over the plume cross-section and multiplied by the mean plume transport speed given by thermal IR imagery. We restrict our flux assessment to March 7 during which both types of measurement were conducted simultaneously.

The procedure to derive IAs is illustrated in Fig. 5 for SC plume emission. We first used the cumulative $\mathrm{H}_{2} \mathrm{~S}$ concentration profile shown in Fig. 5d. As previously observed in March 2006 (Section 4.2), this profile shows two distinct gas contributions from the northern and southern sections of SC venting fracture and is best fitted by a double Gaussian function:

$\left[\mathrm{H}_{2} \mathrm{~S}\right]_{x}=\mathrm{a}_{1} e^{\left(-\left(\frac{x-\mathrm{b}_{1}}{\mathrm{c}_{1}}\right)^{2}\right)}+\mathrm{a}_{2} e^{\left(-\left(\frac{x-\mathrm{b}_{2}}{\mathrm{c}_{2}}\right)^{2}\right)}$

where $\left[\mathrm{H}_{2} \mathrm{~S}\right]$ is the concentration (in ppm), $x$ is the horizontal length in plume's cross section (in $\mathrm{m}$ ), and $\mathrm{a}_{1}, \mathrm{~b}_{1}, \mathrm{c}_{1}, \mathrm{a}_{2}, \mathrm{~b}_{2}$, and $\mathrm{c}_{2}$ are the fitconstants for Gaussians 1 and 2 that take respective values of 32.6, $43.1,9.8,20.4,34.8$ and 33.5. We then used the results of vertical profiles (e.g. Fig. 5e) to derive the $Y$ dependence of $\mathrm{H}_{2} \mathrm{~S}$ plume concentrations. The latter is best fitted with the following polynomial function:

$\left[\mathrm{H}_{2} \mathrm{~S}\right]_{\mathrm{y}}=-0.78 \mathrm{y}^{5}+0.05 \mathrm{y}^{4}+27.3 \mathrm{y}^{3}-96 \mathrm{y}^{2}+119 \mathrm{y}-0.91$

where y is the height above ground (in $\mathrm{m}$ ). Functions (1) and (2) were then combined to obtain numerical values of a $\left[\mathrm{H}_{2} \mathrm{~S}\right]_{x y}$ concentration function over the entire cross-section of the plume, which is taken as ellipsoidal (Fig. 5b). Integration of this function yields a total $\mathrm{H}_{2} \mathrm{~S}$ amount of $3940 \mathrm{ppm} \cdot \mathrm{m}^{2}$, or $0.005 \mathrm{~kg} \mathrm{~m}^{-1}$ (Table 3). Multiplied by a plume transport mean speed of $7 \mathrm{~m} \mathrm{~s}^{-1}$ (range: $5-15 \mathrm{~m} \mathrm{~s}^{-1}$ ), this amount converts into an average $\mathrm{H}_{2} \mathrm{~S}$ flux of $0.035 \pm 0.010 \mathrm{~kg} \mathrm{~s}^{-1}$ or $3.0 \pm 0.8 \mathrm{t} / \mathrm{d}$. This is about three times higher than our $\mathrm{H}_{2} \mathrm{~S}$ flux estimate of $\sim 1 \mathrm{t} / \mathrm{d}$ in March 2006. Such a difference goes beyond the uncertainties introduced by the use of different analytical tools in 2006 and 2012 and thus suggests a slight (but detectable) sulfur flux increase at SC vent in the 6-year interval, coherent with the observed increase of degassing activity. Using the average bulk composition of SC plume (Table 2), we 


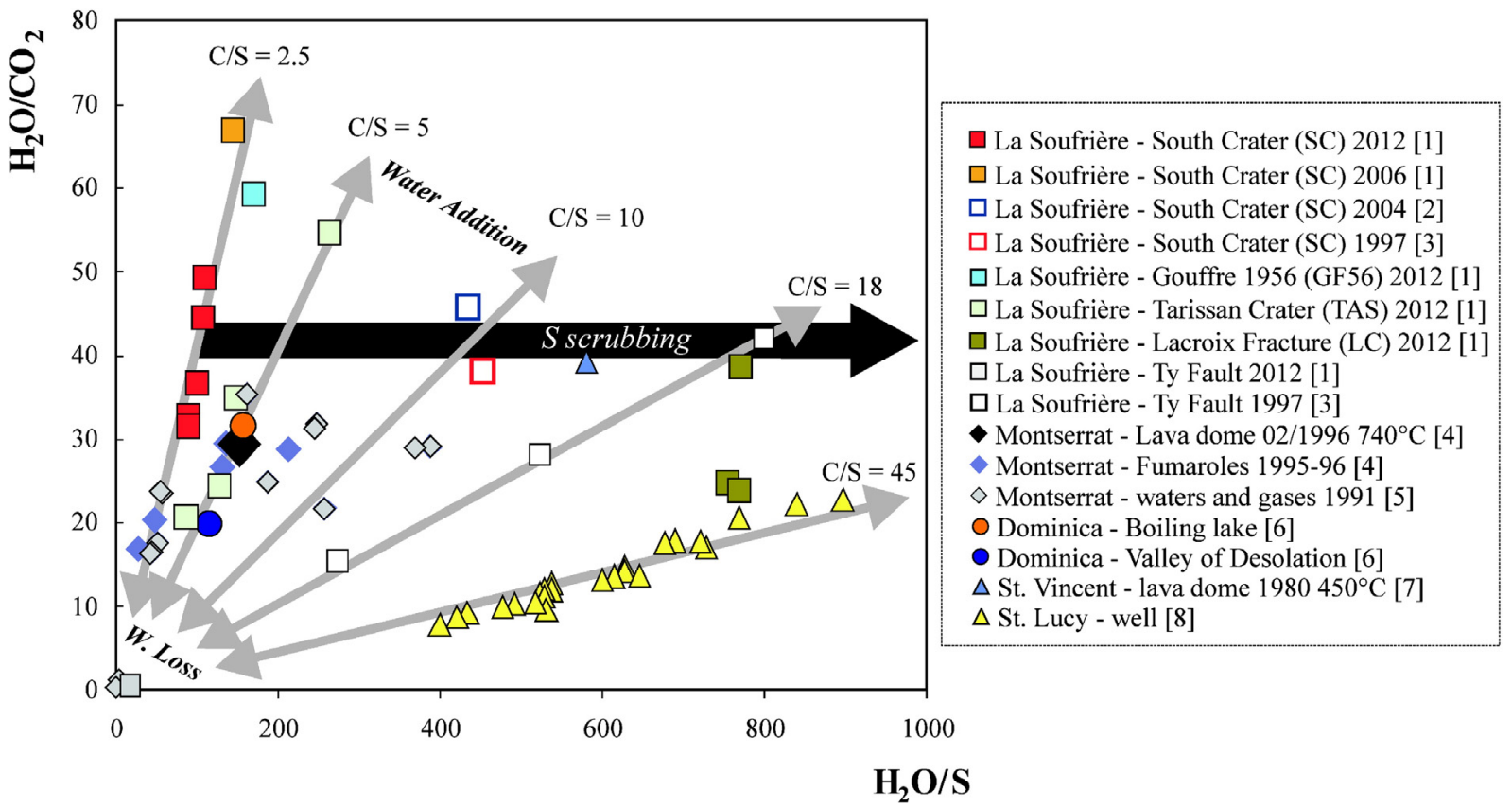

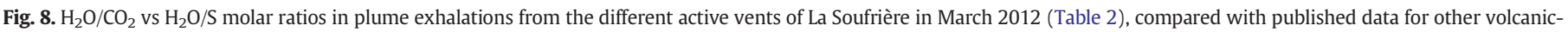

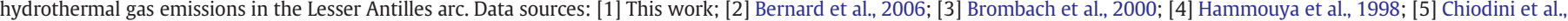
1996; [6] Di Napoli et al., 2013; [7] Allard, 1981; [8] D'Amore et al., 1990.

then compute a total gas flux of $\sim 160 \mathrm{t} / \mathrm{d}( \pm 25 \%)$, with $\mathrm{H}_{2} \mathrm{O}(\sim 150 \mathrm{t} / \mathrm{d})$ and $\mathrm{CO}_{2}(9 \mathrm{t} / \mathrm{d}$ ) as main contributors (Table 3$)$. This corresponds to a total volumetric output of about $5 \mathrm{~m}^{3} \mathrm{~s}^{-1}$ of purely volcanic fluid at ambient pressure. Since SC volcanic plume entrains and heats abundant ambient humid air (Section 5.1), we emphasize that volumetric flux assessment based on simple thermal imagery of the bulk plume could overestimate the actual flux of volcanic steam, whereas the latter is determined specifically by direct MultiGAS analysis.

By applying the same procedure to our dataset for the volcanic plume from TAS crater (Fig. 5) we obtain an $\mathrm{H}_{2} \mathrm{~S}$ flux of $1.0 \pm 0.2 \mathrm{t} / \mathrm{d}$ and a bulk fluid flux of $60 \pm 15 \mathrm{t} / \mathrm{d}$ (Table 3 ) from this vent. While being 2.5 times less productive than SC, TAS emitted in 2012 about as much gas as SC in 2006 (Table 3), which illustrates the strength of renewed activity at that crater in recent years. Moreover, taking account of $~ 45 \%$ sulfur scrubbing in TAS crater lake (Section 5.1 and Fig. 8), the sulfur gas supply to this crater may actually be $\sim 1.5 \mathrm{t} / \mathrm{d}$. We have no data for the chlorine flux from TAS, which leads to somewhat underestimate the total $\mathrm{Cl}$ fumarolic output from the volcano. Nevertheless, because water vapour highly predominates in the fumarolic fluid, the total (SC + TAS) fumarolic fluid flux from La Soufrière in March 2012 is correctly evaluated as about $220 \mathrm{t} / \mathrm{d}$. This is much less than the steam flux of $10^{3}-10^{4} \mathrm{t} / \mathrm{d}$ estimated during the 1976-1977 phreatic eruptions or even than the average daily steam flux during that eruptive period (Le Guern et al., 1980). In its present stage of activity La Soufrière thus remains a weak gas emitter. However, it is the second most important spot of volcanic degassing in the Lesser Antilles arc, after Soufriere Hills of Montserrat where lava dome extrusion since 1996 has been accompanied by a time-averaged $\mathrm{SO}_{2}$ flux of $\sim 600 \mathrm{t} /$ day and pulses at $>5000$ t/day (Christopher et al., 2010). La Soufrière emissions are of the same order as those measured at other closed-conduit quiescent volcanoes in degassing unrest. One example of these is Vulcano island (Italy), where characteristic $\mathrm{H}_{2} \mathrm{O}$ and $\mathrm{H}_{2} \mathrm{~S}$ fluxes are comparable (225$580 \mathrm{t} / \mathrm{d}$ and 7.5-8 t/d; Tamburello et al., 2011). But Vulcano also produces 20-27 t/d of $\mathrm{SO}_{2}$ (Tamburello et al., 2011), whereas La Soufrière emits very few $\mathrm{SO}_{2}(\sim 0.2 \mathrm{t} / \mathrm{d}$; Table 3$)$ and hence displays a more typical hydrothermal signature.

Table 3

Steam and gas fluxes from La Soufrière summit fumarolic activity. Comparison with chemical fluxes through thermal water outflow.

\begin{tabular}{|c|c|c|c|c|c|c|}
\hline & South crater & South crater & Tarissan & Total flux & Hot springs & Gas/spring \\
\hline & $03 / 2006$ & $03 / 2012$ & $\overline{03 / 2012}$ & $03 / 2012$ & $\overline{\text { Discharge }^{\mathrm{b}}}$ & $\overline{\text { Flux ratio }}$ \\
\hline Plume speed $(\mathrm{m} / \mathrm{s})$ & 3.6 & 7.0 & 7.0 & & & \\
\hline $\mathrm{H}_{2} \mathrm{~S} \mathrm{IA}^{\mathrm{a}}\left(\mathrm{ppm} \cdot \mathrm{m}^{2}\right)$ & 2610 & 3940 & 1360 & & & \\
\hline $\mathrm{H}_{2} \mathrm{~S}$ flux (tons/day) & 1.0 & 2.8 & 1.0 & 3.8 & 0.17 & 22 \\
\hline $\mathrm{H}_{2} \mathrm{O}$ flux (tons/day) & 75 & 149 & 54 & 203 & 830 & 0.24 \\
\hline $\mathrm{CO}_{2}$ flux (tons/day) & 2.8 & 9.0 & 5.8 & 14.9 & 0.026 & 572 \\
\hline $\mathrm{HCl}$ flux (tons/day) & 0.45 & 1.1 & - & 1.1 & 0.17 & 6.5 \\
\hline $\mathrm{SO}_{2}$ flux (tons/day) & 0.04 & 0.19 & 0.01 & 0.2 & & \\
\hline $\mathrm{H}_{2}$ flux (tons/day) & 0.0014 & 0.003 & 0.17 & 0.17 & & \\
\hline Total (tons/day) & 79 & 163 & 61 & 224 & 830 & 0.3 \\
\hline${ }^{3} \mathrm{He}$ (mole/day) & $5.8 \mathrm{E}-06$ & $2.1 \mathrm{E}-05$ & $1.3 \mathrm{E}-05$ & $3.4 \mathrm{E}-05$ & $1.3 \mathrm{E}-08^{\mathrm{c}}$ & 2600 \\
\hline
\end{tabular}

See the text for details and discussion.

a Integrated amount of $\mathrm{H}_{2} \mathrm{~S}$ in volcanic plume cross-section (see Section 5.1).

b Total chemical fluxes through thermal water outflow, as detailed in Table 4, with dissolved S expressed as $\mathrm{H}_{2} \mathrm{~S}$ for direct comparison with fumarolic emission.

c From Ruzié et al. (2012). 


\subsection{Total volatile output and thermal budget of La Soufrière}

In addition to fumarolic summit degassing, hydrothermal manifestations at La Soufrière include thermal springs and diffuse soil gas emanations whose contribution to the chemical and heat budget of the volcano must also be considered.

Six hot springs issue at high elevation (1145-980 $\mathrm{m}$ a.s.l.) around the lava dome, within $1.4 \mathrm{~km}$ from its top, from within the former crater in which the dome has built (see their location in Villemant et al., 2005). Their chemistry and flow rate are routinely monitored by the volcano Observatory (OVSG-IPGP reports, 1992-2012). These springs contain dissolved helium and $\mathrm{CO}_{2}$ with fumarole-like magmatic isotopic signatures ( $\sim 8$ Ra and -5.4 to $-3.2 \%$, respectively; Allard, 2006; Ruzié et al., 2012, 2013; Jean-Baptiste et al., 2013), as well as magma-derived chlorine (Li et al., 2012). Table 4 lists the spring characteristics relevant to our study. From their average flow rate and chemistry in March 2006 and March 2012, we compute a total hot water outflow of 830 tons $\mathrm{d}^{-1}$ carrying about $0.026 \mathrm{t} / \mathrm{d}$ of carbon $\left(\mathrm{as} \mathrm{CO}_{2}\right), 0.16 \mathrm{t} / \mathrm{d}$ of $\mathrm{S}$ and $0.16 \mathrm{t} / \mathrm{d}$ of $\mathrm{Cl}$ (Table 4). This budget is conservative since some springs (e.g. Ravine Marchand) issue from a wider area than surveyed. It reveals that the thermal water discharge from La Soufrière is four times larger by mass than the fumarolic steam output but contributes comparatively little $\mathrm{CO}_{2}$ $(0.17 \%)$ and a small proportion of S (4.5\%) (Table 3$)$. Its higher relative contribution in chlorine ( $20 \%)$ is consistent with the higher solubility of $\mathrm{HCl}$ than $\mathrm{CO}_{2}$ and $\mathrm{S}$-bearing gas species in groundwater. This comparison demonstrates a gaseous transfer and release of virtually all (>99\%) carbon dioxide and of most (>95\%) of total sulfur through the central conduits of the volcanic pile. A prominent central gas transfer is especially obvious for ${ }^{3} \mathrm{He}$, little soluble in groundwater, whose flux from summit fumaroles is three orders of magnitude higher than its thermal spring discharge (Ruzié et al., 2012; Table 3).

Diffuse soil degassing is a third mode of volatile release at La Soufrière. Diffuse soil emanations of $\mathrm{CO}_{2}$-rich gas were initially identified at the base of the lava dome, in the hydrothermal zone extending along the regional Ty fault (Allard et al., 1998; Fig. 1d). Here as well, the emanating $\mathrm{CO}_{2}$ and He have a magmatic isotopic signature similar to that in summit fumaroles (Allard, 2006; Ruzié et al., 2012; Jean-Baptiste et al., 2013). In March 2006 we performed the very first measurements of soil $\mathrm{CO}_{2}$ fluxes at La Soufrière. Tropical vegetation covering the summit area produces a background biogenic $\mathrm{CO}_{2}$ flux of 0.06 to $0.16 \mathrm{~kg} \mathrm{~m}^{-2} \mathrm{~d}^{-1}$. On the lava dome, made of massive lava (Nicollin et al., 2006), we could not find any gas flux anomaly with respect to this biogenic background, except at a few points of steaming ground surrounding SC vent (Fig. 9a). The only area of intense volcanic soil degassing was again verified along the Ty fault at the base of the dome. In addition to high temperatures (60 to $93^{\circ} \mathrm{C}$ ) and high
$\mathrm{CO}_{2}$ concentrations (from 10 to $100 \mathrm{~mol} \%$ ) at $30-70 \mathrm{~cm}$ depth in the ground, the fault structure is characterized by relatively high $\mathrm{CO}_{2}$ flux values (up to $20 \mathrm{~kg} \mathrm{~m}^{-2} \mathrm{~d}^{-1}$ ) but within only two narrow sections of our profile (Fig. 9b). By integrating the $\mathrm{CO}_{2}$ flux in these two emissive bands and extrapolating to their respective area $(\sim 15 \times 3 \mathrm{~m}$ and $10 \times$ $2 \mathrm{~m}$ ), we crudely estimate a total soil $\mathrm{CO}_{2}$ flux of $0.3 \mathrm{t} / \mathrm{d}$, equivalent to $10 \%$ of the fumarolic $\mathrm{CO}_{2}$ flux in March 2006 and only $2 \%$ of the fumarolic flux in March 2012 (Table 3). Our MultiGAS data for the $\mathrm{H}_{2} \mathrm{O} / \mathrm{CO}_{2}$ (0.7) and $\mathrm{CO}_{2} / \mathrm{H}_{2} \mathrm{~S}$ (24.5) ratios of gas emanations along the Ty fault (Table 2) lead to corresponding fluxes of $0.2 \mathrm{t} / \mathrm{d}$ of steam and $0.02 \mathrm{t} / \mathrm{d}$ of $\mathrm{H}_{2} \mathrm{~S}$. Therefore, in the present stage of activity soil degassing contributes only a minor part to the bulk $\mathrm{CO}_{2}$ and $\mathrm{S}$ emissions from La Soufrière and negligibly to its steam (and heat) output, in agreement with estimates from airborne thermal imaging (Beauducel et al., submitted for publication).

The thermal budget of La Soufrière can thus be quantified from the fluid fluxes associated with both summit fumarolic degassing and thermal spring outflow. As shown above, water vapour constitutes 97-98 mol\% of the fumarolic emission (Tables 1 and 2) and 94\% of its bulk mass output (Table 3). Therefore, the enthalpy of fumarolic activity $\left(\mathrm{Q}_{\text {tot }}, \mathrm{kJ} \mathrm{s}^{-1}\right)$ is essentially due to heat release by cooling and condensation of the volcanic steam flux $\left(\mathrm{M}_{\mathrm{v}}, \mathrm{kg} \mathrm{s}^{-1}\right)$ :

$\mathrm{Q}_{\mathrm{tot}}=\mathrm{M}_{\mathrm{v}} \cdot\left[C_{p, v} \cdot\left(T_{v}-T_{b}\right)+L_{c}+C_{p, l} \cdot\left(T_{b}-T_{a}\right)\right]$

where $C_{p, v}$ is the specific heat $\left(2.0156 \mathrm{~kJ} \mathrm{~kg}^{-1}{ }^{\circ} \mathrm{K}^{-1}\right.$ at $\sim 0.9$ bar $)$ released during cooling of the superheated steam from its exit temperature $T_{v}$ (108.6 in $2006,107.5^{\circ} \mathrm{C}$ in 2012 ) to the water boiling temperature $\left(T_{b}=96.7^{\circ} \mathrm{C}\right)$ at the dome altitude, $L_{c}$ is the latent heat of condensation (2265.55 kJ kg-1 à 0.9 bar), and $C_{p, l}$ is the heat capacity $\left(\sim 4.2 \mathrm{~kJ} \mathrm{~kg}^{-1{ }^{\circ}} \mathrm{K}^{-1}\right)$ of liquid water cooled from $T_{b}$ to the ambient air temperature $T_{a}$. In computing the thermal budget in March 2012 we consider the emissions of superheated steam from SC and of boiling steam $\left(\sim 98{ }^{\circ} \mathrm{C}\right)$ from TAS acid lake. The fumarolic steam flux of $\sim 0.9 \mathrm{~kg} \mathrm{~s}^{-1}$ in March 2006 and $2.6 \mathrm{~kg} \mathrm{~s}^{-1}$ in March 2012 results in respective heat release of $2.3 \times 10^{3}$ and $6.9 \times 10^{3} \mathrm{~kJ} \mathrm{~s}^{-1}$, or 2.3 and 6.9 MW.

From the measured temperature and flow rate of the hot springs (Table 4), we compute a cumulated heat release of $1.1 \mathrm{MW}$ as the waters cool to air temperature at their exit. Although prevalent by mass, the thermal water outflow thus contributes the equivalent of only $17 \%$ of the fumarolic heat release. We therefore assess a total enthalpy budget of about 8 MW from La Soufrière in March 2012. This is about half the power production of the Bouillante geothermal plant (15 MW; Sanjuan and Brach, 1997), 18 km away on the western coast

Table 4

Mean water outflow and $\mathrm{CO}_{2}-\mathrm{S}-\mathrm{Cl}$ budget of La Soufrière thermal springs in March 2006 and March 2012.

\begin{tabular}{|c|c|c|c|c|c|c|c|c|c|c|c|c|}
\hline Spring & Altitude $\mathrm{m}$ a.s.l. & Date & $\mathrm{T}^{\circ} \mathrm{C}$ & $\mathrm{pH}$ & Cond. $\mathrm{mS}$ & Flow rate $1 / \mathrm{min}$ & $\mathrm{HCO}_{3} \mathrm{mg} / \mathrm{l}$ & $\mathrm{SO}_{4} \mathrm{mg} / \mathrm{l}$ & $\mathrm{Cl} \mathrm{mg/l}$ & $\mathrm{CO}_{2}$ tot. $\mathrm{kg} /$ day & S kg/day & $\mathrm{Cl} \mathrm{kg/day}$ \\
\hline Carbet I'Echelle & 1146 & $24 / 03 / 2006$ & 21.2 & 5.19 & 936 & 4.5 & 55.5 & 864.6 & 21.3 & 0.26 & 1.9 & 0.1 \\
\hline Carbet I'Echelle & & $28 / 03 / 2012$ & 20.8 & 5.28 & 1275 & 3.2 & 62.0 & 727.0 & 11.2 & 0.20 & 1.1 & 0.1 \\
\hline Galion & 1100 & $22 / 03 / 2006$ & 44.2 & 4.93 & 1890 & 160 & 36.0 & 720.5 & 244.6 & 5.98 & 55.3 & 56.4 \\
\hline Galion & & $13 / 03 / 2012$ & 47.9 & 5.25 & 3050 & 150 & 35.1 & 679.9 & 457.7 & 5.47 & 48.9 & 98.9 \\
\hline Galion bis & 1100 & $10 / 01 / 2006$ & 41.9 & 5.05 & 1794 & 120 & 25.3 & 569.8 & 193.1 & 3.15 & 32.8 & 33.4 \\
\hline Galion bis & & $13 / 03 / 2012$ & 42.8 & 5.38 & 2380 & 110 & 30.9 & 589.9 & 378.7 & 3.53 & 31.1 & 60.0 \\
\hline Tarade & 1079 & $28 / 03 / 2006$ & 37.2 & 5.86 & 1533 & 139 & 94.0 & 707.3 & 139.1 & 13.6 & 47.3 & 27.9 \\
\hline Tarade & & 09/03/2012 & 41.5 & 5.97 & 2188 & 79 & 107.5 & 681.3 & 183.1 & 8.84 & 25.9 & 20.9 \\
\hline Ravine Marchand & 1015 & $22 / 03 / 2006$ & 43.5 & 5.30 & 1220 & 19.0 & 78.1 & 489.9 & 39 & 1.54 & 4.5 & 1.1 \\
\hline Ravine Marchand & & $13 / 03 / 2012$ & 44.7 & 5.55 & 2094 & 24.2 & 94.8 & 490.6 & 112.8 & 2.38 & 5.7 & 3.9 \\
\hline Pas du Roy & 1008 & $28 / 03 / 2006$ & 33.5 & 5.56 & 940 & 13.3 & 54.3 & 460.1 & 54.7 & 0.75 & 2.9 & 1.0 \\
\hline Pas du Roy & & $09 / 03 / 2012$ & 34.6 & 5.59 & 1213 & 24.6 & 40.9 & 431.2 & 64.8 & 1.05 & 5.1 & 2.3 \\
\hline Bains Jaunes & 981 & $28 / 03 / 2006$ & 30.4 & 5.28 & 723 & 159 & 16.5 & 355.4 & 49.6 & 2.72 & 27.1 & 11.4 \\
\hline Bains Jaunes & & $01 / 03 / 2012$ & 29.6 & 5.35 & 850 & 144 & 16.8 & 285.6 & 50.2 & 2.52 & 22.4 & 12.0 \\
\hline Total flux (kg/day) & & & & & & $830 \times 10^{3}$ & & & & 26 & 156 & 165 \\
\hline
\end{tabular}

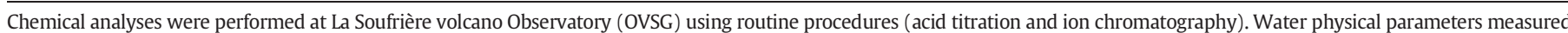

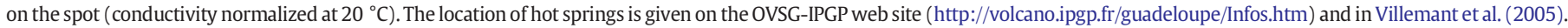


$\mathbf{a}$

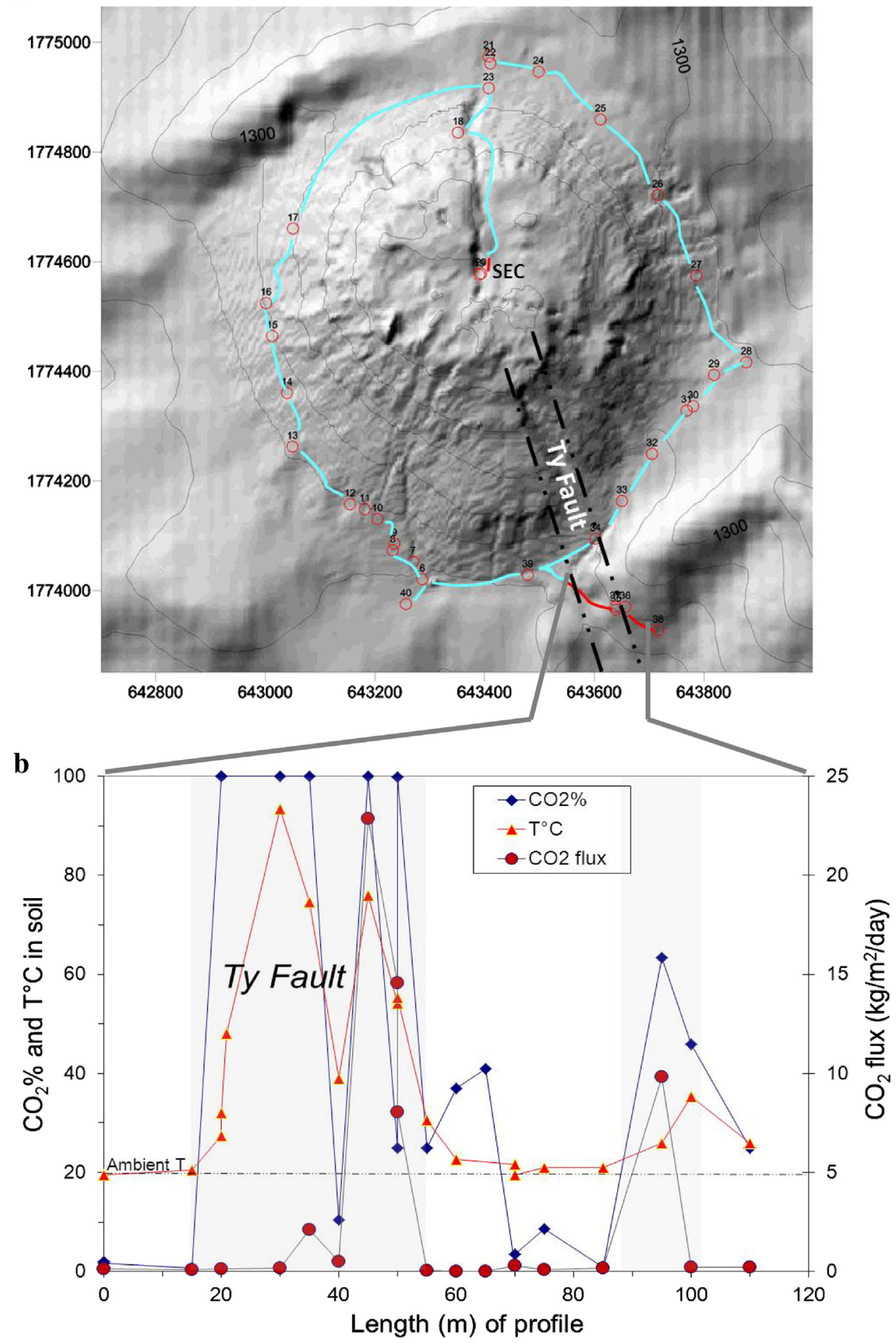

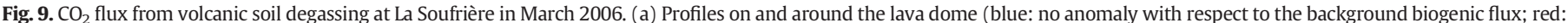

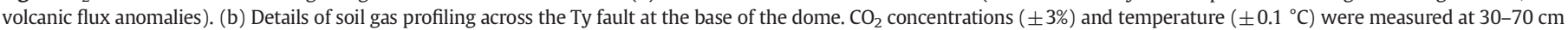

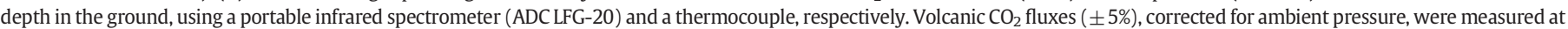

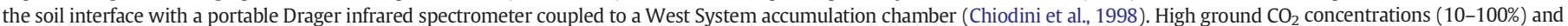
temperature (up to $95^{\circ} \mathrm{C}$ ), as well as high $\mathrm{CO}_{2}$ flux values (up to $20 \mathrm{~kg} \mathrm{~m}^{-2} \mathrm{~d}^{-1}$ ), characterise two narrow bands coinciding with the Ty fault.

of Basse Terre island. Comparing with the contemporaneous seismic energy release is also interesting: over the past ten years the latter averaged $15 \mathrm{MJ} \mathrm{yr}^{-1}$ (OVSG-IPGP reports) which, in terms of instantaneous mechanical energy release, corresponds to a trivial rate of $0.5 \mathrm{~W}$. Therefore, in the present stage of activity the energy budget of La Soufrière is overwhelmingly due to hydrothermal manifestations.

\subsection{Magma degassing supply}

As introduced, La Soufrière hydrothermal activity is sustained by heat and gas transfer from a long-lived (>30 ka; Touboul et al., 2007) andesitic magma reservoir, repeatedly replenished with basalt from below, whose roof stands at about 6-7 km depth beneath the summit 
(Hirn and Michel, 1979; Pozzi et al., 1979; Feuillard et al., 1983; Poussineau, 2005; Boudon et al., 2008). Petrologic experiments on the 1530 AD eruptive products (Poussineau, 2005) constrain that the reservoir is confined under mean P-T-redox conditions of $160 \mathrm{MPa}(\sim 6.5 \mathrm{~km}$ depth), $\sim 875{ }^{\circ} \mathrm{C}$ and $\log f_{\mathrm{O} 2} \sim \mathrm{NNO}+0.8$ (where NNO is the nickel-nickel oxide redox buffer). Continuous gas transfer from this reservoir is evidenced by the magmatic isotopic signatures of $\mathrm{He}, \mathrm{CO}_{2}$ and $\mathrm{Cl}$ in $\mathrm{La}$ Soufrière hydrothermal fluids in the past 35 years (Allard et al., 1982; Allard, 1983, 2006; Van Soest et al., 1998; Pedroni et al., 1999; Li et al., 2012; Ruzié et al., 2012, 2013; Jean-Baptiste et al., 2013). In contrast, $\mathrm{D} / \mathrm{H}$ and ${ }^{18} \mathrm{O} /{ }^{16} \mathrm{O}$ data point to a prominent meteoric derivation of the fumarolic steam through the boiling of local groundwater (Benauges, 1981; Brombach et al., 2000; Allard, 2006 and in preparation). The origin of sulfur may be more complex: its isotopic composition is not known and this element is more susceptible to fractionation during gas-water-rock interactions (Symonds et al., 1994). However, we have shown above that only a small fraction $(<5 \%)$ of total emitted sulfur is actually scrubbed in La Soufrière thermal aquifers (Section 5.3 and Table 3) and, secondly, that fumarolic degassing from SC vent, the least affected by scrubbing (Section 5.1) and responsible for most of the gas output (Section 5.2), has a comparable $\mathrm{CO}_{2} / \mathrm{S}$ ratio as degassing from early andesite extrusion at Soufriere Hills of Montserrat (Fig. 8). Therefore, a co-magmatic derivation of $\mathrm{CO}_{2}$ and $\mathrm{S}$ in SC fumarolic gas and, more broadly, in the deep gas supply to La Soufrière hydrothermal system is a reasonable hypothesis. The predominent release of sulfur as $\mathrm{H}_{2} \mathrm{~S}$ (Table 1) is not only coherent with the hydrothermal temperature of the fumarolic emission but also compatible with thermodynamic computation for magmatic gas on top of the andesitic reservoir: thermodynamic data (Barin and Knacke, 1973) for the equilibrium reaction $\mathrm{H}_{2} \mathrm{~S}$ $+3 / 2 \mathrm{O}_{2}=\mathrm{SO}_{2}+\mathrm{H}_{2} \mathrm{O}$ under the $\mathrm{P}$-T-redox reservoir conditions (Poussineau, 2005) constrain a high $\mathrm{H}_{2} \mathrm{~S} / \mathrm{SO}_{2}$ molar ratio $(\geq 10)$ in the likely water-rich (see below) magmatic gas phase. Now, upon escape from the reservoir and ascent through the crust, this gas phase should become increasingly enriched in $\mathrm{H}_{2} \mathrm{~S}$ over $\mathrm{SO}_{2}$ as it cools and reequilibrates and, subsequently, as it interacts with the shallow hydrothermal system (scrubbing of more soluble $\mathrm{SO}_{2}$ as sulfate).

Based on the above considerations, we can use the volcanic gas fluxes measured in March 2012 and available data for dissolved volatiles in La Soufrière magma in order to tentatively assess the quantity of underground magma from which free gas release supplies the current activity.

Petrologic and geochemical (major and trace elements) data for the erupted products of La Soufrière-Grande Découverte volcanic complex show that they belong to the same differentiation trend as older magmatic series from the Basse Terre Axial Chain and the southernmost Mount Caraïbes (Semet et al., 1981; Boudon et al., 2008) and that their compositional range (from evolved basalt to felsic andesite and rarer dacite) is well explained by fractional crystallization from a parental basalt that replenishes the reservoir from below (Semet et al., 1981; Poussineau, 2005; Touboul et al., 2007; Boudon et al., 2008). Owing to its incompatible behaviour, $\mathrm{K}_{2} \mathrm{O}$ and its content in the evolved magmatic liquids (represented by melt inclusions and glassy matrixes) are reliable indicators of the extent of this differentiation process (Boudon et al., 2008). Volatile abundances in the parental basalt of La SoufrièreGrande Découverte magmas are unknown but an indirect estimate is given by the volatile content of basaltic melt inclusions $\left(48.2 \% \mathrm{SiO}_{2}\right.$, $5.0 \% \mathrm{MgO}$ and $0.6 \% \mathrm{~K}_{2} \mathrm{O}$ ) entrapped in olivines of the least evolved basalts from the nearby Mount Caraïbes massif: these were found to contain about 2 wt.\% $\mathrm{H}_{2} \mathrm{O}, 0.12$ wt.\% S and 0.14 wt.\% Cl (N. Métrich, unpub. data, pers. comm. 2012; Table 5). In comparison, melt inclusions entrapped in pyroxene and plagioclase phenocrysts of La Soufrière andesites contain $4-5$ wt.\% $\mathrm{H}_{2} \mathrm{O}, 0.25-0.30$ wt.\% $\mathrm{Cl}, 0.025$ wt.\% $\mathrm{S}$ and very few ( $\leq 25$ wt. ppm) $\mathrm{CO}_{2}$ (Semet et al., 1981; Poussineau, 2005; Boudon et al., 2008). These latter inclusions are all rhyolitic in composition ( $75 \% \mathrm{SiO}_{2}$ and $2.1 \% \mathrm{~K}_{2} \mathrm{O}$ on average) and represent the most differentiated liquid of crystal-rich (40 wt.\%) felsic andesite stored in the upper part of the magma reservoir (Semet et al., 1981; Poussineau, 2005; Boudon et al., 2008). Their dissolved volatile content well agrees with the respective solubilities of $\mathrm{H}_{2} \mathrm{O}-\mathrm{CO}_{2}$ (Papale et al., 2006), S (Clemente et al., 2004) and Cl (Shinohara, 2009) in rhyolite under the P-T-redox confining conditions of the reservoir (Poussineau, 2005). Amphibole and sulfide globules are absent in La Soufrière evolved products (Poussineau, 2005; Boudon et al., 2008).

Hence, according to the above evidences the magma feeding system of La Soufrière is open to basaltic replenishment at its bottom and to gas escape from its top, supplying hydrothermal emissions at the surface. Since we have no information on the geometry and the degassing mode of this feeding system, here we just attempt to estimate the amount of feeding (basaltic) magma whose degassing would be needed to supply the 2012 volcanic fluxes of magma-derived volatiles. For doing this, we calculate the bulk mass fraction of $\mathrm{H}_{2} \mathrm{O}, \mathrm{S}$ and $\mathrm{Cl}$ exsolved in the magmatic system from the difference between the $\mathrm{K}_{2} \mathrm{O}$-normalized initial concentration of each species in the parental basalt and its $\mathrm{K}_{2} \mathrm{O}$-normalized residual concentration in the rhyolitic melt of andesite on top of the reservoir. Normalizing to $\mathrm{K}_{2} \mathrm{O}$ allows to correct for magma differentiation. The exsolved mass fraction of each volatile is equal to: $1-\left[\left(X_{i} / \mathrm{K}_{2} \mathrm{O}\right)_{r} /\left(X_{i} / \mathrm{K}_{2} \mathrm{O}\right)_{b}\right]$, where $X_{i}$ is its respective concentration (wt.\%) in the rhyolitic $(r)$ and basaltic $(b)$ melts. The results, listed in Table 5, indicate a bulk exsolution rate of $36 \%$ for water, $94 \%$ for sulfur and $45 \%$ for chlorine, corresponding to bulk exsolved amounts of 0.71 wt.\% $\mathrm{H}_{2} \mathrm{O}, 0.10$ wt.\% $\mathrm{S}$ and 0.063 wt.\% $\mathrm{Cl}$ in the overall magmatic system. If one accepts a magmatic derivation of the total flux of

Table 5

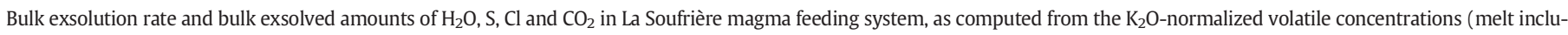

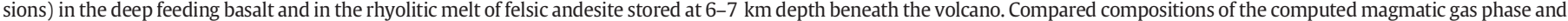
of SC fumarolic fluid emitted in March 2012.

\begin{tabular}{|c|c|c|c|c|c|c|c|c|}
\hline \multirow[t]{2}{*}{ Species } & Basalt $^{\mathrm{a}}$ & Rhyolite $^{\mathrm{b}}$ & $\mathrm{X}_{\mathrm{i}} / \mathrm{K}_{2} \mathrm{O}$ & $\mathrm{X}_{\mathrm{i}} / \mathrm{K}_{2} \mathrm{O}$ & Exsolution & Bulk exsolved & Magmatic & 2012 SC \\
\hline & Wt.\% & Wt.\% & Basalt & Rhyolite & Rate $^{c}$ & Amount (wt.\%) & Gas (mol\%) & Fluid (mol\%) \\
\hline $\mathrm{H}_{2} \mathrm{O}$ & $\sim 2$ & 4.5 & 3.33 & 2.14 & 0.36 & 0.714 & 74 & 96.7 \\
\hline $\mathrm{S}$ & 0.11 & 0.025 & 0.18 & 0.012 & 0.94 & 0.103 & 6.0 & 0.9 \\
\hline $\mathrm{Cl}$ & 0.14 & 0.27 & 0.23 & 0.13 & 0.45 & 0.063 & 3.3 & 0.4 \\
\hline $\mathrm{CO}_{2}$ & $0.4^{\mathrm{d}}$ & 0.0025 & 0.7 & 0.0012 & 0.998 & 0.399 & 17 & 2.0 \\
\hline $\mathrm{K}_{2} \mathrm{O}$ & 0.6 & 2.1 & & & & & & \\
\hline
\end{tabular}

\footnotetext{
a Dissolved $\mathrm{H}_{2} \mathrm{O}, \mathrm{S}$ and $\mathrm{Cl}$ contents of basaltic melt inclusions entrapped in olivines of most primitive basalt from the nearby Mount Caraïbes massif (N. Métrich, unpub. data, pers. comm. 2012), taken as analogue of La Soufrière feeding basalt.

b Dissolved $\mathrm{H}_{2} \mathrm{O}, \mathrm{S}, \mathrm{Cl}$ and $\mathrm{CO}_{2}$ contents of rhyolitic melt inclusions entrapped in pyroxene and plagioclase phenocrysts of La Soufrière andesites (Semet et al., 1981; Poussineau, 2005; Boudon et al., 2008).

c Bulk exsolution rate $=1-\left[\left(X_{i} / \mathrm{K}_{2} \mathrm{O}\right)_{r} /\left(X_{i} / \mathrm{K}_{2} \mathrm{O}\right)_{b}\right]$, where $X_{i}$ is the respective concentration of each volatile in the rhyolitic $(r)$ and basaltic $(b)$ melts.

d $\mathrm{CO}_{2}$ content in the feeding basalt (this work) was estimated from the $\mathrm{CO}_{2} / \mathrm{S}$ ratio of SC fumarolic fluid and the bulk amount of degassing basaltic melt $\left(\sim 1400 \mathrm{~m}^{3} \mathrm{~d}^{-1}\right)$ inferred to supply the fumarolic flux of sulfur, assumed to be magmatic in origin (see text for explanation).
} 
elemental sulfur emitted in 2012 from SC vent ( $2.64 \mathrm{t} / \mathrm{d}$ ) and supplied to Tarissan crater ( $1.5 \mathrm{t} / \mathrm{d}$ after correction for scrubbing, Section 5.1), its scaling to the bulk amount of $\mathrm{S}$ exsolved in the system implies a magmatic gas supply from $4 \times 10^{6} \mathrm{~kg} \mathrm{~d}^{-1}$ or $1400 \mathrm{~m}^{3} \mathrm{~d}^{-1}\left(0.016 \mathrm{~m}^{3} \mathrm{~s}^{-1}\right)$ of basaltic melt with a density of $2800 \mathrm{~kg} \mathrm{~m}^{-3}$. Due to uncertainty on the fumarolic sulfur flux (25\%, Section 5.2$)$ and other variables $\left(\mathrm{K}_{2} \mathrm{O}\right.$, S), this estimate is probably accurate to within $30-35 \%$. Such a relatively small rate reflects the modest gas fluxes from La Soufrière despite its current degassing unrest.

When referred to the above estimate, the total fumarolic flux of magma-derived carbon dioxide from SC and TAS vents in $2012(15 \mathrm{t} / \mathrm{d})$ constrains a bulk exsolved amount of 0.4 wt.\% $\mathrm{CO}_{2}$ in the magmatic system. Since carbon dioxide exsolves still earlier than sulfur during basalt degassing and is at the detection limit in rhyolitic melt inclusions of $\mathrm{La}$ Soufrière andesite (Poussineau, 2005), this amount should well approximate the original $\mathrm{CO}_{2}$ content of the parental basalt (Table 5). In fact, it falls within the typical $\mathrm{CO}_{2}$ range for arc basaltic magmas (Wallace, 2005). Including carbon dioxide, the feeding system may thus contain $\sim 1.3$ wt.\% of total exsolved gas whose molar composition, on top of the reservoir ( $160 \mathrm{MPa}$ ), would average $~ 74 \% \mathrm{H}_{2} \mathrm{O}, 17 \% \mathrm{CO}_{2}, 6 \% \mathrm{~S}$ and $3 \%$ $\mathrm{Cl}$ (Table 5). We compute that the escape of this magmatic gas phase from the equivalent of $1400 \mathrm{~m}^{3} \mathrm{~d}^{-1}$ of basalt beneath La Soufrière can provide a magmatic flux of $28 \mathrm{t} / \mathrm{d}$ of $\mathrm{H}_{2} \mathrm{O}$ and $2.5 \mathrm{t} / \mathrm{d}$ of chlorine. Comparing with the fumarolic emission rates of $\mathrm{H}_{2} \mathrm{O}(\sim 200 \mathrm{t} / \mathrm{d})$ and $\mathrm{Cl}(1.1 \mathrm{t} / \mathrm{d})$ in March 2012 (Table 3), we verify the following two points: (a) an extensive (7 times) meteoric dilution of the magmatic water prior to reaching the surface, which fully agrees with isotopic data for the fumarolic steam (Benauges, 1981; Brombach et al., 2000; Allard, 2006) and with the much more hydrous composition of SC fumarolic fluid ( $97 \%$ $\mathrm{H}_{2} \mathrm{O}$ ) compared to the reservoir-derived magmatic gas (Table 5). Such a feature is well accounted for by the huge tropical rainfall rate of $\sim 10$ $\mathrm{m}$ per year on top of La Soufrière, a great part of which infiltrates into the volcanic edifice (Villemant et al., 2005); and (b) a substantial removal of the magma-derived chlorine by dissolution in La Soufrière hydrothermal aquifers, in good agreement with elemental balances (Section 5.3) and $\mathrm{Cl}$ isotope data (Li et al., 2012).

\section{Conclusions}

Based on in situ plume measurements and gas analysis at La Soufrière of Guadeloupe in March 2006 and March 2012, we provide the first direct estimate of steam and gas emission rates from the summit fumarolic activity of this volcano during a period of degassing unrest. We find a total gas release of $\sim 80$ tons/day in 2006 and $\sim 220$ tons/day in 2012, most of which as steam, whose temporal increase is consistent with enhanced degassing activity and the reactivation of new vents. Including thermal water outflow and diffuse soil degassing, mass balance calculations show that summit fumarolic degassing contributes most of the volatile budget of La Soufrière and most of its thermal output, evaluated as about 8 MW in March 2012. Heat output from the hydrothermal manifestations widely exceeds the energy released by contemporaneous seismic activity.

MultiGAS analysis of $\mathrm{H}_{2} \mathrm{O}, \mathrm{CO}_{2}, \mathrm{H}_{2} \mathrm{~S}, \mathrm{SO}_{2}$ and $\mathrm{H}_{2}$ plume emissions from the different summit vents of La Soufrière, performed for the first time, allows us to define a common fluid end-member that is emitted almost unmodified at the most active South Crater (SC) but variably affected by shallow secondary alterations at other vents. As shown by isotopic data, this fluid contains magma-derived helium, $\mathrm{CO}_{2}$ and $\mathrm{Cl}$, likely released from the magma reservoir confined at 6-7 $\mathrm{km}$ depth beneath the volcano. An ultimate magmatic derivation of sulfur is also likely, whereas $\mathrm{H}_{2} \mathrm{O}$ originates predominantly from the boiling of meteoric groundwater. Based on this information, on petro-geochemical data for La Soufrière magmas and their dissolved volatile content, we have tentatively assessed the amount of basalt feeding La Soufrière magmatic system whose underground degassing is needed to supply the current volcanic gas fluxes. Assuming a magmatic derivation of sulfur, we find that the release of free magmatic gas derived from about $1400 \mathrm{~m}^{3}$ /day ( $\pm 30-35 \%)$ of feeding basalt could well account not only for the gas fluxes measured in March 2012, but also for the isotopic composition and the specific chemical behaviour of each volatile species upon interaction with the hydrothermal system. Comparing the volcanic fluxes of $\mathrm{H}_{2} \mathrm{O}$ and $\mathrm{Cl}$ with the potential magmatic gas supply from depth verifies both extensive meteoric dilution of the magmatic water and substantial scrubbing of magmatic chlorine in the hydrothermal system, in good agreement with isotopic data and chemical balances.

Our present estimate of the rate of magmatic gas release from the feeding system of La Soufrière is the very first one to be quantified from volcanic gas flux measurements. Given its assumptions and uncertainties, this estimate will have to be refined in future based on improved knowledge of the volcano plumbing system. Since the gas and heat budget of the volcano is one key indicator of its level of activity, we recommend that regular gas flux survey becomes undertaken at La Soufrière, in complement to routine gas sampling and analysis. Such a survey should permit to quantify temporal changes in the mass balance between underground magma degassing and hydrothermal supply to the surface emissions, and hence to better distinguish the precursory signals of a forthcoming magmatic eruption from temporary dynamic changes in the hydrothermal system. Automated MultiGAS monitoring already conducted on several volcanoes worldwide (Aiuppa et al., 2011) demonstrates its great potential for continuous gas survey of a dormant volcano such as La Soufrière. Combining such a survey with periodic MuliGAS measurement of the volcanic plume discharge, as described in this study, would thus open new perspectives for improved monitoring and forecasting of La Soufrière behaviour in future.

\section{Acknowledgements}

This study was carried out within two research projects funded by CNRS-INSU (ACI Project "Structure et Stabilité de la Zone Sommitale de la Soufrière de Guadeloupe", 2004-2006) then by ANR ("DOMOSCAN", ANR-08-RISKNAT-002-01). It also benefited of supports from the ERC grant agreement $n^{\circ} 1305377$ (PI: A. Aiuppa) of the European Research Council (FP7/2007-2013) and from Palermo University (Italy). We are grateful to Nicole Métrich (IPGP) for communication of her unpublished results for dissolved volatiles in Mount Caraïbes basalt. We acknowledge the help of the staff of Guadeloupe Volcano Observatory (OVSG), of Jean-Bernard de Chabalier and Olivier Coutant, and thank the Guadeloupe National Park. This is an IPGP contribution \#\#\#.

\section{References}

Aiuppa, A., Federico, C., Giudice, G., Gurrieri, S., 2005a. Chemical mapping of a fumarolic field: La Fossa Crater, Vulcano Island (Aeolian Islands, Italy). Geophys. Res. Lett. 32, $1-4$.

Aiuppa, A., Inguaggiato, S., McGonigle, A.J.S., O'Dwyer, M., Oppenheimer, C., Padgett, M.J., Rouwet, D., Valenza, M. 2005b. $\mathrm{H}_{2}$ S fluxes from Mt. Etna, Stromboli and Vulcano (Italy) and implications for the global volcanic sulfur budget. Geochim. Cosmochim. Acta 69-7, 1861-1871. http://dx.doi.org/10.1016/j.gca.2004.09.018.

Aiuppa, A., Franco, A., von Glasow, R., Allen, A.G., D'Alessandro, W., Mather, T.A., Pyle, D.M., Valenza, M., 2007. The tropospheric processing of acidic gases and hydrogen sulphide in volcanic gas plumes as inferred from field and model investigations. Atmos. Chem. Phys. 7, 1-10.

Aiuppa, A., Shinohara, H., Tamburello, G., Giudice, G., Liuzzo, M., Moretti, R., 2011. Hydrogen in the gas plume of an open-vent volcano, Mount Etna, Italy. J. Geophys. Res. B: Solid Earth 116 (10) (art. no. B10204).

Aiuppa, A., Giudice, G., Liuzzo, M., Tamburello, G., Allard, P., Calabrese, S., Chaplygin, I. McGonigle, A.J.S., Taran, Y., 2012. First volatile inventory for Gorely volcano, Kamchatka. Geophys. Res. Lett. 39 (6) (art. no. L06307).

Allard, P., 1981. Composition chimique et isotopique des gaz émis par le nouveau dôme andésitique de la Soufrière de St. Vincent (Antilles). CR Acad. Sci. Paris D 510, 721-724.

Allard, P., 1983. The origin of hydrogen, carbon, sulfur, nitrogen and rare gases in volcanic exhalations: evidence from isotope geochemistry. In: Tazieff, H., Sabroux, J.C. (Eds.), Forecasting Volcanic Events. Elsevier, Amsterdam, pp. 337-386.

Allard, P., 2006. 30 years after the 1976-77 seismo-phreatic crisis of Soufrière volcano, Guadeloupe island (FWI): revisited source mechanism(s) and implications. Abstract Presented at GARAVOLCAN International Meeting, Tenerife, Canaries, 21-27 May 2006. 
Allard, P., Dimon, B., Morel, P., 1982. Mise en évidence d'hélium primordial dans les émissions gazeuses de la Soufrière de Guadeloupe, petites Antilles. Abstract Presented at the 10th Réun. Ann. Sci. Terre., Paris, March 1982, p. 454.

Allard, P., Delibrias, G., Dimon, B., Labeyrie, J., 1983. Implications of carbon and helium isotopes in volcanic gases from la Soufrière of Guadeloupe, Lesser Antilles. Abstract Presented at 1983 IAVCEI Symp. on Volcanic Gases, Hamburg, Germany. 43.

Allard, P., Carbonnelle, J., Métrich, N., Loyer, H., Zettwoog, P., 1994. Sulphur output and magma degassing budget of Stromboli. Nature 368, 326-330.

Allard, P., Hammouya, G., Parello, F., 1998. Diffuse magmatic soil degassing at Soufrière of Guadeloupe, Antilles. C. R. Acad. Sci. Paris Earth Planet. Sci. 327, 315-318.

Bagnato, M., Allard, P., Parello, F., Aiuppa, A., Calabrese, S., Hammouya, G., 2009. Mercury gas emissions of from La Soufrière volcano, Guadeloupe (lesser Antilles). Chem. Geol. 226, 276-282.

Barin, I., Knacke, O., 1973. Thermochemical Properties of Inorganic Substances. SpringerVerlag, Berlin and New York (921 pp.)

Beauducel, F., Gaudin, D., Coutant, O., Richon, P., de Chabalier, J.-B., Delacourt, C., Allemand, P. Mass and heat flux balance of La Soufrière volcano (Guadeloupe) from infrared thermal imagery. J. Volcanol. Geotherm. Res. (submitted for publication).

Benauges, S., 1981. Etude géochimique et isotopique et circulation des eaux de sources chaudes, sources froides et rivières aux abords du volcan de la Soufrière-Guadeloupe(PhD thesis) Université Pierre et Marie Curie, Paris, France (91 pp.).

Bernard, M.-L., Molinié, J., Petit, R.-H., Beauducel, F., Hammouya, G., Marion, G., 2006. Remote and in situ plume measurements of acid gas release from La Soufrière volcano, Guadeloupe. J. Volcanol. Geotherm. Res. 150 (4), 395-409.

Bigot, S., Hammouya, G., 1987. Surveillance hydrogéochimique de la Soufrière de Guadeloupe, 1979-1985: diminution d'activité ou confinement? C. R. Acad. Sci. Paris 304 (13), 757d.60.

Boichu, M., Villemant, B., Boudon, G., 2011. Degassing at La Soufrière de Guadeloupe volcano (Lesser Antilles) since the last eruptive crisis in 1975-77: result of a shallow magma intrusion? J. Volcanol. Geotherm. Res. 203 (3-4), 102-112.

Boudon, G., Semet, M.P., Vincent, P.M., 1989. The evolution of la Grande Découverte (La Soufrière) volcano, Guadeloupe, F.W.I. In: Latter, J.H. (Ed.), VolcanicHazards:Assessment and Monitoring. IAVCEI Proceedings inVolcanology, volume 1. Springer-Verlag, Berlin, pp. 86-109.

Boudon, G., Komorowski, J.-C., Villemant, B., Semet, M.P., 2008. A new scenario for the last magmatic eruption of La Soufrière of Guadeloupe (Lesser Antilles) in 1530 A.D.: evidence from stratigraphy radiocarbon dating and magmatic evolution of erupted products. J. Volcanol. Geotherm. Res. 178 (3), 474-490.

Brombach, T., Marini, L., Hunziker, J.-C., 2000. Geochemistry of the thermal springs and fumaroles of Basse-Terre Island, Guadeloupe, Lesser Antilles. Bull. Volcanol. 61 (7), 477-490.

Chaperon, P., L'Hote, Y, Vuillaume, G., 1985. Les ressources en eau de surface de la Guadeloupe. ORSTOM, Monographies Hydrologiques, 7, p. 571 (Paris, France).

Chiodini, G., Cioni, R., Frullani, A., Guidi, M., Marini, L., Prati, F., Raco, B., 1996. Fluid geochemistry of Montserrat Island, West Indies. Bull. Volcanol. 58, 380-392.

Chiodini, G., Cioni, R., Guidi, M., Raco, B., Marini, L., 1998. Soil $\mathrm{CO}_{2}$ flux measurements in volcanic and geothermal areas. Appl. Geochem. 13, 543-552.

Christopher, T., Edmonds, M., Humphreys, M.C.S., Herd, R.A., 2010. Volcanic gas emissions from Soufrière Hills Volcano, Montserrat 1995-2009, with implications for mafic magma supply and degassing. Geophys. Res. Lett. 37, L00E04. http://dx.doi.org/10. 1029/2009GL041325.

Clemente, B., Scaillet, B., Pichavant, M., 2004. The solubility of sulphur in hydrous rhyolitic melts. J. Petrol. 45 (11), 2171-2196.

D'Amore, F., Rivera, J.R., Giusti, D., Rossi, R., 1990. Preliminary geochemical and thermodynamic assessment of the geothermal resources, Sulphur Springs area, St Lucia, W.I Appl. Geochem. 5, 587-604.

Di Napoli, R., Aiuppa, A., Allard, P., 2013. First Multi-GAS based characterisation of the Boiling Lake volcanic gas (Dominica, Lesser Antilles). Ann. Geophys. 56, S0559. http://dx.doi.org/10.4401/ag-6277.

Feuillard, M., Allègre, C.J., Brandeis, G., Gaulon, R., Le Mouel, J.L., Mercier, J.C., Pozzi, J.P., Semet, M.P., 1983. The 1975-1977 crisis of la Soufrière de Guadeloupe (F.W.I): a still-born magmatic eruption. J. Volcanol. Geotherm. Res. 16 (3-4), 317-334.

Fiorani, L., Colao, F., Palucci, A., Poreh, D., Aiuppa, A., Giudice, G., 2011. First-time lidar measurement of water vapour flux in a volcanic plume. Opt. Commun. 284 (5), 1295-1298.

Gerlach, T.M., Doukas, M.P., McGee, K.A., Kessler, R., 1999. Airborne detection of diffuse carbon dioxide emissions at Mammoth Mountain, California. Geophys. Res. Lett. 26, 3661-3664.

Giggenbach, W., Sheppard, D., 1989. Variations in the temperature and chemistry of White Island fumarole discharges 1972-85. N. Z. Geol. Surv. Bull. 103, 119.126.

Hammouya, G., Allard, P., Jean-Baptiste, P., Parello, F., Semet, M., Young, S., 1998. Pre- and syn-eruptive geochemistry of volcanic gases from Soufriere Hills of Montserrat, West Indies. Geophys. Res. Lett. 25 (19), 3685-3688.

Hirn, A., Michel, B., 1979. Evidence of migration of main shocks during major seismovolcanic crises of la Soufrière (Guadeloupe, Lesser Antilles) in 1976. J. Volcanol. Geotherm. Res. 6 (3-4), 295-304.

Javoy, M., Pineau, F., Delorme, H., 1986. Carbon and nitrogen isotopes in the mantle. Chem. Geol. 57 (1-2), 41-62.

Jean-Baptiste, P., Allard, P., Fourré, E., Ruzié, L., Aiuppa, A., Parello, F., 2013. Helium isotope systematics of the volcanic gases and thermal springs of Guadeloupe island, Lesser Antilles. IAVCEI Gen. Assembly, July 2013, Kagoshima, Japan, Session 2G (abstract).

Jean-Baptiste P., Allard P., Fourré E., Parello F., Aiuppa A., Helium isotope systematics of volcanic gases and thermal springs in Guadeloupe island, Lesser Antilles, J. Volcanol. Geotherm. Res. (submitted for publication).
Komorowski, J.-C., Boudon, G., Semet, M., Beauducel, F., Antenor-Habazac, C., Bazin, S., Hammouya, G., 2005. Guadeloupe. In: Lindsay, J.M., Robertson, R.E.A., Shepherd, J.B., Ali, S. (Eds.), Volcanic Atlas of the Lesser Antilles. Seismic Research Unit, The University of the West Indies, Trinidad, pp. 65-102.

Kopp, H., et al., 2011. Deep structure of the central Lesser Antilles Island Arc: relevance for the formation of continental crust. Earth Planet. Sci. Lett. 304, 121-134. http://dx.doi org/10.1016/j.epsl.2011.01.024.

Le Guern, F., Bernard, A., Chevrier, R.M.,1980. Soufriere of Guadeloupe 1976-1977 eruption: mass and energy transfer and volcanic health hazards. Bull. Volcanol. 43, 578-592.

Li, L., Jendrzejewski, N., Aubaud, C., Bonifacie, M., Crispi, O., Dessert, C., Agrinier, P., 2012. Isotopic evidence for quick freshening of magmatic chlorine in the Lesser Antilles arc volcanoes. Abstract Presented at AGU Fall Meeting, 3-5 December 2012, San Francisco, USA, V53B-2831.

Marty, B., Tolstikhin, I.N., 1998. $\mathrm{CO}_{2}$ fluxes from mid-ocean ridges, arcs and plumes. Chem. Geol. 145, 233-248.

Mori, N., Chang, K.-A., 2003. Introduction to MPIV, user reference manual. http://www. oceanwave.jp/softwares/mpiv/ (14 pp.).

Nicollin, F., Gibert, D., Beauducel, F., Boudon, G., Komorowski, J.-C., 2006. Electrical tomography of La Soufrière of Guadeloupe Volcano: field experiments, 1D inversion and qualitative interpretation. Earth Planet. Sci. Lett. 244 (3-4) 709-724.

O'Dwyer, M., Padgett, M.J., McGonigle, A.J.S., Oppenheimer, C., Inguaggiato, S., 2003. Real time measurements of volcanic $\mathrm{H}_{2} \mathrm{~S} / \mathrm{SO}_{2}$ ratios by UV spectroscopy. Geophys. Res. Lett. 30. http://dx.doi.org/10.1029/2003GL017246.

Observatoire Volcanologique et Sismologique de la Guadeloupe (OVSG-IPGP), 1992-2012. Bilan mensuel de l'activité volcanique de La Soufrière et de la sismicité régionale, IPGP-CNRS-INSU-Conseil Général de la Guadeloupepublished online at: http://volcano.ipgp.fr/guadeloupe/Infos.htm.

Oppenheimer, C., 2010. Ultraviolet sensing of volcanic sulfur emissions. Elements 6 , 87-92.

Papale, P., Moretti, R., Barbato, D., 2006. The compositional dependence of the saturation surface of $\mathrm{H}_{2} \mathrm{O}+\mathrm{CO}_{2}$ fluids in silicate melts. Chem. Geol. 229, 78-95.

Pasquill, F., 1961. The estimation of the dispersion of windborne material. Meteorol. Mag. 90, 33-49.

Pedroni, A., Hammerschmidt, K., Friedrichsen, H., 1999. He, Ne, Ar, and C isotope systematics of geothermal emanations in the Lesser Antilles Islands Arc. Geochim. Cosmochim. Acta 63 (3-4), 515-532.

Poussineau, S., 2005. Dynamique des magmas andésitiques: approche expérimentale et pétrostructurale; application à la Soufrière de Guadeloupe et à la Montagne Pelée(Ph.D thesis) Université d'Orléans, France (302 pp.).

Pozzi, J., Le Mouel, J.-L., Rossignol, J., Zlotnicki, J., 1979. Magnetic observations made on La Soufrière volcano (Guadeloupe) during the 1976-1977 crisis. J. Volcanol. Geotherm. Res. 5, 217-237.

Roberts, T.J., Brabana, C.F., Oppenheimer, C., Martin, R.S., Freshwater, R.A., Dawson, D.H., Griffiths, P.T., Cox, R.A., Saffell, J.R., Jones, R.L., 2012. Electrochemical sensing of volcanic gases. Chem. Geol. 332-333, 74-91.

Ruzié, L., Moreira, M., Crispi, O., 2012. Noble gas isotopes in hydrothermal volcanic fluids of La Soufrière volcano, Guadeloupe, Lesser Antilles arc. Chem. Geol. 304-305, 158-165.

Ruzié, L., Aubaud, C., Moreira, M., Agrinier, P., Dessert, C., Gréau, C., Crispi, O., 2013. Carbon and helium isotopes in thermal springs of La Soufrière volcano (Guadeloupe, Lesser Antilles): implications for volcanological monitoring. Chem. Geol. 359, 70-80 http://dx.doi.org/10.1016/j.chemgeo.2013.09.008.

Samper, A., Quidelleur, X., Mollex, D., Lahitte, P., 2007. Timing of effusive volcanism and collapse events within an oceanic arc island: Basse-Terre, Guadeloupe archipelago (Lesser Antilles Arc). Earth Planet. Sci. Lett. 258, 175-191. http://dx.doi.org/10 1016/j.EPSL.2007.03.030.

Sanjuan, B., Brach, M., 1997. Etude hydrogéochimique du champ géothermique de Bouillante (Guadeloupe). BRGM Report, Orléans, France, R39880 (84 pp.).

Schwandner, F.M., Carn, S.A., Corradini, S., Merucci, L., Salerno, G., La Spina, A., 2012 Space-borne detection of volcanic carbon dioxide anomalies: the importance of ground-based validation networks. Proceedings of the 2012 EGU meeting, Vienna, Abstract n. EGU2012-6820.

Semet, M., Vatin-Pérignon, N., Vincent, P., Joron, J.L., 1981. L'éruption du XVlème siècle de la Soufrière de Guadeloupe: mélange de magmas et dynamismes éruptifs. Bulletin PIRPSEV-CNRS, Paris, 60, pp. 1-63.

Shinohara, H., 2005. A new technique to estimate volcanic gas composition: plume measurements with a portable multi-sensor system. J. Volcanol. Geotherm. Res. $143,319-333$

Shinohara, H., 2009. A missing link between volcanic degassing and experimental studies on chlorine partitioning. Chem. Geol. 263, 51-59. http://dx.doi.org/10.1016/j. chemgeo.2008.12.001.

Symonds, R.B., Rose, W.I., Bluth, G.J.S., Gerlach, T.M., 1994. Volcanic gas studies: methods results, and applications. Rev. Mineral. 30, 1-66.

Symonds, R., Mizutani, Y., Briggs, P., 1996. Long-term geochemical surveillance of fumaroles at Showa-Shinzan dome, Usu Volcano, Japan. J. Volcanol. Geotherm. Res. 73 (177-211), 1996.

Tamburello, G., Kantzas, E.P., McGonigle, A.J.S., Aiuppa, A., Giudice, G., 2011. UV camera measurements of fumarole field degassing (La Fossa crater, Vulcano Island). J. Volcanol. Geotherm. Res. 199 (1-2), 47-52.

Todesco, M., Chiodini, G., Macedonio, G., 2003. Monitoring and modelling hydrotherma fluid emission at La Solfatara (Phlegrean Fiels, Italy): an interdisciplinary approach to the study of diffuse degassing. J. Volcanol. Geotherm. Res. 125, 57-79.

Touboul, M., Bourdon, B., Villemant, B., Boudon, G., Joron, J.L., 2007. ${ }^{238} \mathrm{U}-{ }^{230}{ }^{2}$ h $-{ }^{226}$ Ra disequilibria in andesitic to dacitic lavas of the 1440 Soufrière eruption (Guadeloupe): processes and timescales of magma differentiation. Chem. Geol. 246, 181-206. 
Van Soest, M.C., Hilton, D.R., Kreulen, R., 1998. Tracing crustal and slab contributions to arc magmatism in the lesser antilles island arc using helium and carbon relationships in geothermal fluids. Geochim. Cosmochim. Acta 62 (19-20), 3323-3335.

Villemant, B., Hammouya, G., Michel, A., Semet, M.P., Komorowski, J.-C., Boudon, G.,

Cheminée, J.-L., 2005. The memory of volcanic waters: Shallow magma degassing revealed by halogen monitoring in thermal springs of La Soufrière volcano (Guadeloupe, Lesser Antilles). Earth Planet. Sci. Lett. 237 (3-4), 710-728.
Wallace, P.J., 2005. Volatiles in subduction zone magmas: Concentrations and fluxes based on melt inclusion and volcanic gas data. J. Volcanol. Geotherm. Res. 140, 217-240.

Zlotnicki, J., Boudon, G., Le Mouël, J.-L., 1992. The volcanic activity of La Soufrière of Guadeloupe (Lesser Antilles): structural and tectonic implications. J. Volcanol. Geotherm. Res. 49 (1-2), 91-104. 